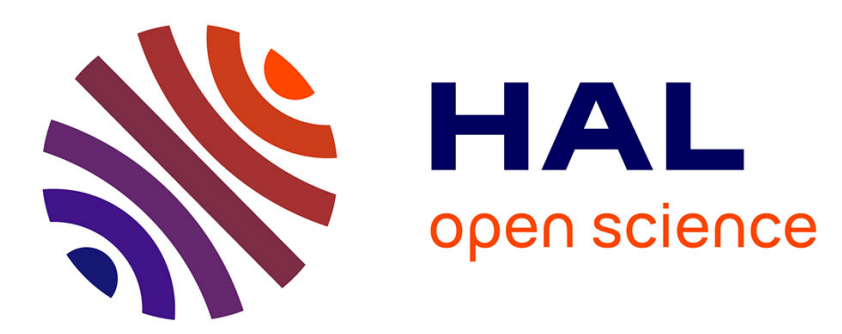

\title{
Omega-3 polyunsaturated fatty acids and oxygenated metabolism in atherothrombosis.
}

Michel Guichardant, Catherine Calzada, Nathalie Bernoud-Hubac, Michel Lagarde, Evelyne Véricel

\section{- To cite this version:}

Michel Guichardant, Catherine Calzada, Nathalie Bernoud-Hubac, Michel Lagarde, Evelyne Véricel. Omega-3 polyunsaturated fatty acids and oxygenated metabolism in atherothrombosis.. BBA Biochimica et Biophysica Acta, 2014, 1851 (4), epub ahead of print. 10.1016/j.bbalip.2014.09.013 . inserm-01072309

\section{HAL Id: inserm-01072309 https://www.hal.inserm.fr/inserm-01072309}

Submitted on 8 Oct 2014

HAL is a multi-disciplinary open access archive for the deposit and dissemination of scientific research documents, whether they are published or not. The documents may come from teaching and research institutions in France or abroad, or from public or private research centers.
L'archive ouverte pluridisciplinaire HAL, est destinée au dépôt et à la diffusion de documents scientifiques de niveau recherche, publiés ou non, émanant des établissements d'enseignement et de recherche français ou étrangers, des laboratoires publics ou privés. 


\section{Omega-3 polyunsaturated fatty acids and oxygenated metabolism in atherothrombosis}

Michel Guichardant*, Catherine Calzada, Nathalie Bernoud-Hubac, Michel Lagarde, Evelyne Véricel.

Affiliations: Université de Lyon, UMR 1060 Inserm (CarMeN), UMR 1397 INRA, INSA-Lyon, IMBL, Villeurbanne, France

${ }^{*}$ Corresponding author: Michel Guichardant, INSA-Lyon, Bldg IMBL 20 Ave. A. Einstein, 69621 Villeurbanne Cedex France

e-mail: michel.guichardant@insa-lyon.fr

Tel: 33472438215

Fax: 33472438524

Key-words: platelets, peroxidation, dioxygenases, $\alpha$-linolenic acid, eicosapentaenoic acid, docosahexaenoic acid 


\begin{abstract}
Numerous epidemiological studies and clinical trials have reported the health benefits of omega-3 polyunsaturated fatty acids (PUFA), including a lower risk of coronary heart diseases. This review mainly focuses on the effects of alpha-linolenic (ALA), eicosapentaenoic (EPA) and docosahexaenoic (DHA) acids on some risk factors associated with atherothrombogenesis, including platelet activation, plasma lipid concentrations and oxidative modification of low-density lipoproteins (LDL). Special focus is given to the effects of marine PUFA on the formation of eicosanoids and docosanoids, and to the bioactive properties of some oxygenated metabolites of omega-3 PUFA produced by cyclooxygenases and lipoxygenases. The antioxidant effects of marine omega-3 PUFA at low concentrations and the pro-oxidant effects of $\mathrm{DHA}$ at high concentrations on the redox status of platelets and LDL are highlighted. Non enzymatic peroxidation end-products deriving from omega-3 PUFA such as hydroxy-hexenals, neuroketals and EPA-derived isoprostanes are also considered in relation to atherosclerosis.
\end{abstract}




\section{Introduction}

Atherothrombosis and its complications are a major cause of morbidity. Indeed, in 2010 , one out of four deaths worldwide was due to ischemic heart diseases and stroke [1], and the prevalence could be growing. This pathophysiology is complex, involving many risk factors (such as inflammation, hyperlipidemia, diabetes mellitus, hypertension, smoking, age...) and interactions between vascular and blood cells. The relationship between coronary heart diseases and fatty acids has been known since the sixties when epidemiologic studies showed a strong association between the high incidence of such diseases and high intake of saturated fatty acids [2]. At the opposite, about a decade later, some evidence from studies of Bang and Dyerberg $[3,4]$ indicated that $n-3$ or omega $(\omega)-3$ polyunsaturated fatty acids (PUFA) consumption could protect against cardiovascular diseases (CVD). Numerous epidemiological and clinical trials have reported the cardioprotective effects of omega-3 PUFA [5-8]. However, other contemporary clinical trials show controversial data regarding the association of omega-3 PUFA and cardiovascular points $[9,10,11,12,13,14]$. Neutral results of recent intervention trials could be due to heterogeneity of patients (age of the patients, time enrollment in the clinical trial after myocardial infarctions, level of omega-3 PUFA erythrocyte at baseline: omega-3 index [15]) but also be due to differences in the omega-3 PUFA supplements (EPA, DHA alone or in combination, or fish oil), their dose and duration of the supplementation. In addition, increased optimal medical therapy (including statins) [14] could induce an improvement in cardioprotection. Thus, all these discrepancies could explain the differences between intervention trials and epidemiological studies since the Multi-Ethnic study published in 2013 [16] suggest that increased consumption of omega-3 PUFA may prevent CVD.

The omega-3 PUFA family is one of the biologically relevant fatty acid family which mainly includes the precursor alpha-linolenic acid (ALA; 18:3 $\omega 3$ ), stearidonic acid

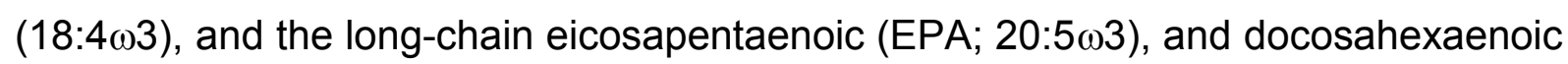

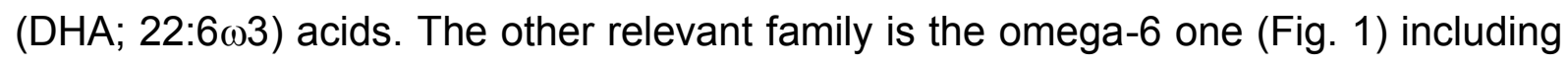

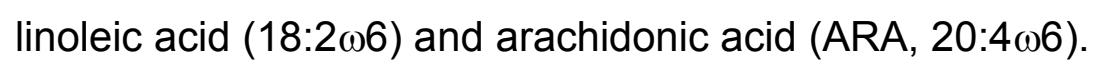

To date, most studies concern the cardioprotective effects of ALA, EPA and DHA which would be the main focus of this review. 


\section{Non-marine omega-3 fatty acids and cardiovascular risk}

Compared to long-chain PUFA, there is less compelling evidence that plant-derived ALA may reduce the cardiovascular risk although meta-analyses of dietary and biomarker studies concluded that increased consumption of ALA reduces the risk of fatal coronary heart disease [17] and confers cardiovascular benefits [18]. Dietary ALA may display anti-thrombotic effects, independently of its conversion to EPA, by indexinhibiting arterial thrombus formation and decreasing collagen- and thrombininduced platelet aggregation [19]. Supplementation with ALA may also decrease some inflammatory markers in dyslipidemic patients [20], resulting in antiinflammatory effects. Studies on the effects of dietary ALA on plasma lipid concentrations are contradictory. Altogether, dietary ALA had no effect, moderately decreased or even increased plasma triacylglycerols (TAG) concentrations [21]. No changes were generally observed in plasma, low-density lipoproteins (LDL) and highdensity lipoproteins (HDL) cholesterol although lipoproteins were enriched in ALA and EPA following ALA supplementation [22]. It should be added that ALA is poorly converted into longer chain PUFA and mainly partitioned toward beta-oxidation $[23,24]$. Recent evidence indicates that ALA is also metabolized into mono- and dihydroxylated compounds by $15-/ \omega 6$-lipoxygenase, with the latter which might account for part of ALA anti-inflammatory and anti-thrombotic effects [25].

Besides ALA, a few studies focused on stearidonic acid (SDA, 18:4 13 ). SDA is the direct product of ALA via the $\triangle 6$-desaturase action. Because $\triangle 6$-desaturase is a ratelimiting enzyme in humans [26], SDA could represent a sustainable alternative to ALA $[27,28]$. In vitro studies showed that the addition of SDA, pre-coated onto albumin to isolated human platelets inhibits agonist-induced aggregation to the same extent as EPA [29]. Human studies have shown that the consumption of SDA, provided as an ethyl ester, leads to an enrichment of plasma phospholipids, red blood cells [30] and peripheral blood mononuclear cells [31] into EPA and DPA, but

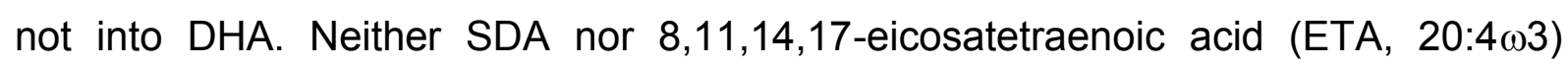
increased in response to dietary SDA. Although SDA did not significantly modify plasma cholesterol concentrations in healthy subjects [32,33], dietary echium oil (containing $14 \%$ SDA as total fatty acids) decreased plasma TAG in 
hypertriglyceridemic patients [30]. Further studies are required to determine the effects of SDA on other cardiovascular risk factors and to uncover oxygenated derivatives of SDA putatively displaying biological activities.

Much less is known on the putative effects of ETA, an intermediate fatty acid between SDA and EPA. It has been described to be as potent as EPA in inhibiting prostaglandin $\mathrm{H}$ synthase (PGHS) activity [34].

\section{Marine PUFA and some factors associated with atherothrombosis}

\section{$\underline{\text { 3.1 Marine PUFA and plasma lipids }}$}

Hypertriglyceridemia is recognized as a risk factor for cardiovascular disease. There is strong evidence that the administration of high doses (2-4 g/day) of omega-3 PUFA (mainly EPA and DHA) to hypertriglyceridemic patients leads to a significant reduction of plasma TAG [35,36], notably in chylomicrons and very low-density lipoproteins (VLDL) particles, thus improving cardiovascular health. The hypotriglyceridemic effects of omega-3 PUFA are dependent on the background dietary fat intake, the dose administered, and the baseline plasma TAG concentrations [37]. Regarding the mechanism of action, the effects are partly due to a decreased hepatic synthesis of TAG and to an increased clearance of chylomicrons [38,39] and VLDL from the circulation. Prescription of omega-3 PUFA in combination with cardiovascular drugs has also to be taken into account since adding statins to omega-3 PUFA may lower TAG levels to a greater extent than statins alone in hypertriglyceridemic patients [40]. Administration of fish oils to hypertensive patients treated with an angiotensin converting enzyme (ACE) inhibitor may further decrease plasma TAG [41].

Considering plasma total cholesterol levels, fish oils or omega-3 PUFA concentrates have generally no significant effect on total cholesterol. Ingestion of fish oils or DHA may lead to very modest increases in LDL and HDL cholesterol which are likely to be related to lower TAG concentrations and/or genetic factors [42]. Some studies showed indeed that supplementation with fish oils may raise LDL cholesterol and total cholesterol concentrations in individuals with an apoE4 allele [43,44]. In 
addition, some studies showed indeed that supplementations wiHowever, some studies showed that omega-3 PUFA may impact cholesterol levels in lipoprotein subclasses. Supplementation with DHA [45] or omega-3 PUFA [46] may increase LDL particle size and consequently large LDL particles rather than small and dense LDL ones, shifting the lipoprotein profile to a less atherogenic situation [47]. The intake of fish oils [48] or high doses of DHA (4g/d for 6 weeks), but not of EPA [45], may result in increased concentrations of HDL cholesterol, especially HDL2. The mechanism of action of DHA could be related to decreased lipid transfer protein activity [49].

\subsection{Effects of marine PUFA on platelet function}

Numerous studies have been conducted with EPA and DHA because these fatty acids are present in the diet of Greenland Inuits (mainly in the form of marine oils and seafood) [50], and found in their plasma lipids [51]. The role of platelets in hemostasis and thrombosis is known for a long time and well defined but more recently, a new concept has emerged stating that platelets play a central role in the atherothrombotic process [52,53]. Because of the pivotal role of platelets, some studies focused on the effect of omega-3 long chain PUFA on platelet function. The first one was reported by Dyerberg and Bang [54] showing that Inuits had attenuated platelet reactivity. Since then, platelet aggregation was found to be diminished [5559] after omega-3 fatty acids intake and even after ingestion of low doses of omega-3 PUFA [60,61]. The heterogeneity of observed results [62] is probably due to great variability of numerous factors including target populations, quantities of omega-3 PUFA, sources of these fatty acids, duration of supplementation. However, a metaanalysis conducted by Gao et al. [63] has demonstrated that omega-3 PUFA are associated with a significant reduction of platelet aggregation. Considering that most experimental feeding studies have been performed with an EPA and DHA mixture, it is difficult to determine the own effect of each PUFA. Pure sources of EPA, DPA or DHA provide more information. After supplementation with EPA, von Schacky and Weber [7] found a decreased platelet reactivity and an increased docosapentaenoic acid (DPA; 22:5 13 ), an intermediate between EPA and DHA (Fig. 1). In addition, low intake of EPA may reduce platelet aggregation, without changing the fatty acid 
platelet composition $[64,65]$. In the same way, following supplementation with DHA [7], platelet function was reduced and a retroconversion of DHA in DPA and EPA was evidenced. Such a retroconversion occurred with normal dietary amounts of DHA, and the rate, calculated by Brossard et al. [66] after ingestion of trace amounts of $\left[{ }^{13} \mathrm{C}\right] \mathrm{DHA}-\mathrm{TAG}$, was relatively low (1.4\%). More recently, we performed a doseresponse study with middle-aged healthy volunteers ingesting increasing amounts of DHA (200, 400, 800 and $1600 \mathrm{mg} /$ day) for two weeks each dosage. We found that DHA supplementation led to a dose-dependent increase of DHA in platelet phospholipids, an increase of EPA after $1600 \mathrm{mg}$ DHA/day while DPA decreased [67], in agreement with results observed by Conquer and Holub [68]. In addition, platelet reactivity was decreased after 400 and $800 \mathrm{mg} \mathrm{DHA} /$ day [67]. They are only a limited number of studies with DPA suggesting it might be more potent than EPA and DHA to inhibit platelet aggregation [69]. Thus, the relationship between EPA, DPA and DHA in the inhibition of platelet function is not clear. It is difficult to precisely attribute the effects to each PUFA, and their beneficial and complementary effects could well be linked to formation or diminution of specific eicosanoids and/or docosanoids.

\section{Marine PUFA and enzymatic oxidized products}

4.1 Effects of marine PUFA on oxygenated metabolites (eicosanoids and docosanoids)

The beneficial effects of marine oils have been largely discussed in terms of effects on arachidonic acid (ARA) oxygenated metabolites. Dietary omega-3 PUFA compete with ARA for acylation into cellular phospholipids [57] and one of the proposed explanations for the prevention of atherosclerosis by omega-3 PUFA may be due to changes in eicosanoid formation. Eicosanoids are signaling lipid metabolites from 20 carbon fatty acids, including prostaglandins, prostacyclin, leukotrienes, hydroxyderivatives and epoxy-derivatives. When platelet activation occurs, ARA is released from phospholipids and oxygenated to give pro-aggregatory prostanoids, mainly thromboxane $A_{2}\left(T x A_{2}\right)$. ARA is also oxygenated by 12-lipoxygenase to provide 12hydroperoxyeicosatetraenoic acid (12-HpETE) [70] (Fig. 2). In presence of EPA, the ARA-derived eicosanoids shift to EPA-derived metabolites [71,72] which are less 
vaso-constrictive and have less potent effect on platelet aggregation [73], which leads to overall antithrombotic activities. Indeed, $\mathrm{TxA}_{2}$, formed by PGH synthase (COX-1)/Tx synthase from ARA, is a pro-aggregatory and vaso-constricting substance [64] while $\mathrm{TxA}_{3}$, formed from EPA, is weakly pro-aggregatory [72]. Also, the conversion of EPA to $\mathrm{TXA}_{3}$ is much lower than ARA to $\mathrm{TxA}_{2}$ [75]. In addition, incorporation of EPA and DHA to membrane phospholipids leads to an inhibition of $\mathrm{TXA}_{2} / \mathrm{PGH}_{2}$ receptor binding as shown by the reduction of platelet sensitivity to a thromboxane receptor agonist [76]. Accordingly, we showed that supplementation with low doses of EPA and DHA, or DHA alone, decreased platelet basal $\mathrm{TxB}_{2}$ concentration $[60,64,67]$.

For more than 50 years, aspirin is used as an antiplatelet medication. The acetylation of Ser 529 in human COX-1 by aspirin [77] inhibits the production of $\mathrm{TXA}_{2}$. Some studies have reported the action of aspirin in combination with omega-3 PUFA. In healthy subjects, omega-3 PUFA can enhance the anti-thrombotic effects of aspirin [78]. Moreover, adding omega-3 PUFA may improve the response to aspirin in aspirin-resistant patients [79]. In the same way, the administration of omega-3 PUFA in combination with aspirin and clopidogrel (an anti-aggregatory drug) decrease platelet aggregation in patients after percutaneous coronary intervention (The OMEGA-PCI) [80].

Omega-3 PUFA may also modify the blood levels of several coagulation factors but the results are conflicting [81]. However in the OMEGA-PCI intervention, the authors have shown that adding omega-3 PUFA to aspirin and clopidogrel prescription in coronary artery disease patients decreases thrombin formation and favorably alters fibrin clot properties. Their findings indicate novel antithrombotic effects induced by omega-3 PUFA [82].

There is some evidence that DPA also inhibits the cyclooxygenase activity but enhances the formation of 12-hydroxyeicosatetraenoic acid (12-HETE) [83]. Moreover, anti-thrombotic effects of these PUFA might also be endotheliumdependent. The 3-series prostacyclin (Fig. 2), synthesized from EPA by endothelial cells, had the same anti-aggregatory effects as the 2-series prostacyclin from ARA [84]. DPA has been shown to inhibit prostacyclin formation but its effect may be attributed to retroconversion of DPA to EPA [85]. 
In addition, cytochrome P450-dependent metabolites of EPA and DHA may also function as mediators of the vaso-dilatory and cardio-protective effects of omega-3 PUFA [86]. Dietary EPA/DHA supplementation results in a tissue-specific accumulation of epoxides derived from EPA and DHA, that are 17,18-epoxyeicosatetraenoic and 19,20-epoxy-docosapentaenoic acids. These omega-3-derived epoxides display anti-arrhythmic actions at nanomolar concentrations [87].

As with ARA, EPA and DHA are substrates of lipoxygenases (LOX). Numerous endproducts mono-, di-and tri-hydroxy derivatives can be formed. Such oxygenated lipid mediators can be produced enzymatically or non-enzymatically.

\section{$\underline{4.2 \text { Effect of enzymatic-derived lipid mediators from omega-3 fatty acids }}$}

The role of chronic inflammation in atherosclerosis which involves leukocytes infiltration in the arterial intima is well established and its resolution offers novel approaches. Lipoxygenase pathways play an important role since they are involved in the recruitment of leukocytes and also in the formation of lipid mediators deriving from omega-6 and omega-3 PUFA [88].

Long chain omega-3 PUFA such as EPA and DHA are also precursors of potent antiinflammatory compounds. Among them, resolvin E1 (RvE1) from EPA $[89,90]$ exhibits an inhibition of neutrophil activation associated with a decrease of their adhesion to the endothelium as well as a decrease of oxidative stress as assessed by lower ROS formation. Interestingly, its formation is enhanced by aspirin [91] which is also known to inhibit cyclooxygenases. RvE1 is an inhibitor of both ADP-induced and thromboxane receptor agonist U46619-stimulated aggregation in platelet-rich plasma in a concentration-dependent manner [92].

EPA can also be metabolized by cyclooxygenase into $\mathrm{PGH}_{3}$ which is then converted to the alternative 3-series $\mathrm{PGs}, \mathrm{PGD}_{3}, \mathrm{PGI}_{3}, \mathrm{PGE}_{3}$ and $\mathrm{PGF}_{3} \alpha$ [93-95]. $\mathrm{PGD}_{3}$ is also converted to the cyclopentenone products, $15 d-P \mathrm{GD}_{3}, P G J_{3}$, and $15 d-P G J_{3}[96,97]$ (Fig. 3). Prostanoids derived from EPA have less inflammatory activities compared with those produced from ARA [98-100]. $\mathrm{PGD}_{3}$ was described as a potential circulating antithrombotic agent [98]. $\mathrm{PGD}_{3}$ also antagonizes the migration of neutrophils across endothelial cells mediated by $\mathrm{PGD}_{2}$ [101]. $\mathrm{PGE}_{3}$ is less proinflammatory than $\mathrm{PGE}_{2}$ [102]. $15 \mathrm{~d}-\mathrm{PGJ}_{3}$ has been shown to increase the secretion 
of adiponectin (a plasma protein adipocytokine showing anti-atherogenic, insulinsensitizing, and anti-inflammatory properties) by adipocytes partly via a peroxisome proliferator-activated receptor-gamma-dependent mechanism [97].

EPA and DHA are substrates of platelet 12-lipoxygenase to produce monohydroxyderivatives including 12 hydroxy-eicosapentaenoic acid (12-HEPE) and 14-hydroxydocosahexaenoic acid (14-HDoHE), which inhibit thromboxane-induced platelet aggregation and aortic contraction [103] and may antagonize the thromboxane action by interfering with their receptor sites [104]. DHA also leads to potent antiinflammatory resolvin D1 (RvD1) and D2 (RvD2). RvD1 enhances both nitric oxide and prostacyclin production in endothelial cells, decreases adhesion receptors and the formation of ROS and pro-inflammatory cytokines. RvD2 is mainly produced by dendritic cells. It inhibits the PMN infiltration into inflamed tissues, decreases PMN activation and promotes phagocytosis and clearance of apoptotic cells. On the other hand, DHA is also converted into protectin D1 (PD1) which is a potent antiinflammatory agent. PD1 exerts potent agonist actions on macrophages and vascular endothelial cells that can control the magnitude of the local inflammatory response involved in atherosclerosis [105]. However, PD1 had no effect on agonist-induced platelet aggregation at the tested concentrations ( $1 \mathrm{nM}$ to $100 \mathrm{nM}$ ) [92]. Moreover, protectin DX (PDX), a stereo and geometric isomer of PD1, produced from DHA via a dioxygenation mechanism by 15-LOX [106], exhibits anti-aggregatory properties. PDX inhibits platelet aggregation induced by collagen, ARA and U-46619 at concentrations as low as $300 \mathrm{nM}$. PDX inhibits cyclooxygenase-1 (COX-1) and also competes with the receptor of thromboxane $A_{2}$ [107]. These properties are linked to the E,Z,E configuration of the conjugated double bonds/triene motif [107]. PDX also exhibits anti-inflammatory properties in reducing the production of ROS by inhibiting NADPH oxidase and cyclooxygenase-2 (COX-2) activities [108]. It is noteworthy to state that the weak structural difference between these geometric and stereo-isomers (PD1 \& PDX) has important consequences on their biological activities, as it has recently been pointed out [109]. Other PUFA can also be converted by 15-LOX into dihydroxylated fatty acids having the same E,Z,E motif (Fig. 4), collectively named poxytrins and sharing the anti-aggregatory properties. Recent investigations reveal that poxytrins synthesized from ALA, called linotrins (Fig. 4), display anti-aggregatory 
properties as well, and one of them inhibits the 5-lipoxygenase activity in human neutrophils [25].

Another metabolite derived from DHA has been recently discovered in activated macrophages which converts DHA into 14S,21-diHDHA and 14R,21-diHDHA via 12lipoxygenase and cytochrome P450 oxygenase. These metabolites promote wound healing and microvasculature formation and may partially represent the molecular mechanisms for macrophage pro-healing function [110].

Besides this enzymatic peroxidation giving bioactive oxygenated metabolites, PUFA are obviously susceptible to the non-enzymatic peroxidation.

\section{Marine PUFA and non enzymatic peroxidation}

\subsection{Effects of omega-3 PUFA upon non enzymatic lipid peroxidation}

An excess of ROS, resulting from either their overproduction and/or insufficient activity of antioxidant defense systems, disturbs the physiological balance between pro- and anti-oxidant systems leading to injurious consequences. Lipid peroxides byproducts namely malondialdehyde (MDA), 4-hydroxy-alkenals, isoketals/neuroketals and isoprostanes/neuroprostanes are formed and are implicated in the etiology of a number of diseases, including cardiovascular ones [111]. Amongst PUFA, marine PUFA are highly oxidizable owing to the presence of 5 or 6 double bonds in the fatty acyl chain. Clinical studies using large doses of omega-3 PUFA indeed reported an increased lipid peroxidation in plasma [112,113] and lipoproteins [114,115] Moreover, in vitro, we have found that large amounts of EPA and/or DHA induce lipid peroxidation in platelets [116,117] whereas low DHA concentrations decrease it. Our results clearly evidenced a bimodal effect of DHA with antioxidant and pro-oxidant effects at low and high concentrations, respectively [118]. Ex vivo, we first showed that the ingestion of $100 \mathrm{mg}$ EPA per day for two months by elderly people increased platelet vitamin $\mathrm{E}$ concentration while decreasing thrombin-induced platelet aggregation [65]. We next reported that the intake of $150 \mathrm{mg}$ EPA and $30 \mathrm{mg}$ DHA for 6 weeks resulted in increased vitamin $E$ and decreased MDA concentrations in platelets from elderly people [60]. More recently, we found that supplementation of healthy men with $200 \mathrm{mg}$ DHA per day for two weeks increased significantly platelet 
vitamin E while urinary isoprostane (IsoP) formation decreased [67]. At the opposite, the supplementation of these same healthy men with $1600 \mathrm{mg}$ per day for two weeks increased urinary IsoP formation [67]. In addition, we showed that supplementation with doses of DHA ranging from 200 to $800 \mathrm{mg} \mathrm{DHA}$ /day increased alpha-tocopherol concentrations, decreased MDA concentrations and lowered the susceptibility of LDL to oxidation [119]. In addition, 4-hydroxy-hexenal (4-HHE), a major aldehyde product of omega-3 fatty acids, was increased following supplementation with 800 and 1600 mg DHA/day while 4-hydroxy-nonenal (4-HNE) concentrations did not vary throughout the DHA supplementation periods. The antioxidant effects of DHA might have been due to its concomitant peroxidation, reflected by the production of 4-HHE. DHA might be a target for free radicals and then might spare the endogenous vitamin $E$ at low supplementation levels. Once oxidation reached a threshold level, the free radical chain reaction of lipid peroxidation might have exceeded the protection supplied by DHA, leading to pro-oxidant effects. In agreement with our results on 4HHE, Ishikado et al. [120] recently reported that supplementation with dietary fish oil led to increased HHE aortic concentrations and increased the expression of the antioxidant enzyme heme oxygenase-1, and endothelium-dependent vasodilatation. As reviewed very recently [121], potential molecular mechanisms to explain the antioxidant effects of omega-3 fatty acids would be the quenching of ROS as well as direct inhibition of NADPH oxidase 4 (Nox-4) by DHA [122]. Altogether, our results obtained in healthy subjects $[67,119,123]$ reinforce the antioxidant potential of low omega-3 PUFA intake as originally described in elderly subjects displaying increased oxidative stress $[60,65]$ and in dyslipidemic diabetic patients [124].

\section{$\underline{5.2 \text { Effect of non-enzymatic lipid mediators deriving from omega- } 3 \text { fatty acids }}$}

Actives aldehydes, including 4-HHE (Fig. 5), can readily react with free primary amine and thiol groups, such as histidine and lysine, and cysteine residues, to generate Schiff base and Michael adducts [125-128]. They are being considered as possible causal agents of different diseases such as chronic inflammation and atherogenesis. Moreover, 4-oxo-nonenal (Fig. 5) which is also a major product of lipid peroxidation $[129,130]$ is more reactive than 4 -HNE towards amino acid residues [131]. Similarly, 4-oxo-hexenal (Fig. 5) is more reactive than 4-HHE. Hydroxy- 
alkenals interact with $L D L$ lysine residues of apoB $[132,133]$. They are recognized by scavenger receptors $[134,135]$ through specific epitopes [136]. Such oxidized LDL are toxic toward endothelial cells by inhibiting their proliferation. 4-HHE, 4-HNE and 4-hydroxy-dodecadienal (4-HDDE) can also form adducts with phosphatidylethanolamine [137-139], and 4-HHE-phosphatidylethanolamine adducts were the main ones detected in retina of streptozotocin-induced diabetic rats [139]. Also, hydroxy-alkenal adducts are present in atherosclerotic lesions [136,140,141]. Monocyte/macrophage CD36 has been shown to play a critical role in the development of atherosclerotic lesions by its capacity to bind and endocytosize oxidized low-density lipoproteins (OxLDL), and is implicated in the formation of foam cells $[142,143]$.

Neuroketals (NKs) are isoketal (IsoK)-like compounds formed via the neuroprostane pathway of DHA peroxidation [144-146] (Fig. 5). Five docosahexaenoyl radicals are initially formed to generate eight D4-NK and eight E4-NK regioisomers. Each regioisomer is theoretically composed of eight racemic diastereoisomers for a total of 128 D4-NKs and 128 E4-NKs. NK isomers are designated by the location of the hydroxyl group. The designation " $\mathrm{D}$ " and " $\mathrm{E}$ " is a carryover from the established prostaglandin nomenclature for PGD and PGE and levuglandins $E$ and $D$ to indicate the location of the ketone moiety. When the keto/oxo group is located in the higher numbered carbon relative to the aldehyde, NK is designed D4 and when the ketone moiety is located in the lower numbered carbon, NKs is designed E4.

These $\mathrm{y}$-ketoaldehydes are some of the most reactive products of lipid peroxidation that covalently modify the lysine residues of proteins at a rate that far exceeds that of 4-HNE [144]. NKs initially form a reversible Schiff base adduct, which then proceeds through a pyrrole to stable lactam and hydroxylactam adducts. Increased levels of NKs-protein adducts are associated with oxidant injury. Moreover, NKs exhibit a remarkable proclivity to form protein cross-links. These $\mathrm{y}$-ketoaldehydes also covalently modify aminophospholipids, forming pyrrole and Schiff base adducts with phosphatidylethanolamines [147-150]. Under oxidizing conditions, the pyrrole adduct generally evolves to form NK-phosphatidylethanolamine lactam and hydroxylactam adducts. 
Because of their capacity to covalently modify proteins, phospholipids and DNA, reactive aldehydes derived from lipid peroxidation have been suggested to be key mediators of oxidant injury including atherosclerotic cardiovascular diseases. IsoKs have been shown to potentiate aggregation of human platelets via p38 MAP kinase, a phenomenon that plays an important role in the pathogenesis of atherosclerosis and its thrombotic complications [151]. IsoKs-protein adducts have also been detected in oxidized LDL [144] and the levels of these adducts increase in blood plasma from patients with atherosclerosis compared with healthy volunteers [152]. Relevant to these pathological states is the activation of the endoplasmic reticulum stress signaling pathways and endothelial activation by IsoKsphosphatidylethanolamine adducts [147], as well as studies showing that IsoKs facilitate mitochondrial calcium dysfunction [153]. It is reasonable to speculate that NKs would have the same effects.

EPA- and DHA-derived IsoPs could also contribute to the beneficial biological effects of fish oil supplementation. For example, the EPA-derived IsoP, 15-F3t-IsoP, unlike 15-F2t-IsoP, does not increase human platelet shape change or aggregation [154]. Moreover, IsoPs generated from the oxidation of EPA are more abundant than those of F2-IsoPs generated from ARA, perhaps because EPA contains more double bonds and is therefore more easily oxidizable [155]. In addition, EPA supplementation markedly reduced levels of arachidonate-derived F2-IsoPs in mouse heart tissues. Such data are especially relevant since F2-IsoPs are generally considered to be pro-inflammatory molecules. Supplementation with EPA decreases F2-IsoP generation and should prevent some diseases associated with increased levels of F2-IsoPs [156].

Recently, targeted lipidomics analyses revealed that both the profiles of EPA and DHA and their corresponding oxygenated metabolites were substantially modulated in plasma and liver. The hepatic F4-neuroprostanes (NPs) level was strongly correlated with the hepatic DHA level. Among all measured metabolites, hepatic F4NPs were mostly negatively correlated with the plaque extent, indicating that F4-NPs are important positive predictors of atherosclerosis prevention [157,158]. 


\section{Specific analytical issues}

Lipid mediators, generally present in fluids in small amount, are usually extracted by solid phase extraction on $\mathrm{C} 18$ or anionic and $\mathrm{C} 18$ cartridges. This procedure can be applied directly to biological fluids, and blood cells after their lysis.

Lipid mediators such as mono-, di- and tri-hydroxylated fatty acids and prostaglandins can be measured together by LC-MS/MS using ESI MRM mode [159161]. The specificity is achieved by their specific retention times and their daughter ions. Their corresponding deuterated internal standards are used for quantification.

The position of the hydroxyl group on the chain may be determined by GC-MS analysis after hydrogenation and derivatization into methyl esters and trimethysilylethers. Such a derivatization allows a specific cleavage to both sides on the carbon which carries the hydroxyl group.

It is of interest to determine the stereochemical configuration of the hydroxy metabolites in order to determine whether the products originate from an enzymatic or non-enzymatic lipid peroxidation. The configuration of the hydroxyl group is achieved by HPLC using chiral columns. The R or $\mathrm{S}$ configuration is obtained by comparison of retention times with chemically-synthesized standards.

The geometry of the double bounds in oxygenated products of PUFA is crucial to be determined as the function of the metabolite may depend on it. The gold standard method is NMR, which requires substantial amounts of highly purified products.

The mechanism of oxidation is solved by using ${ }^{18} \mathrm{O}_{2}$. Indeed, for a double lipoxygenation process, two ${ }^{18} \mathrm{O}$ atoms are present in the final hydroxyl derivatives. In contrast, only one ${ }^{18} \mathrm{O}$ atom is present if the mechanism involves an epoxidation mechanism followed by epoxide opening subsequently to hydration of the intermediate. Such a method has been successfully applied to differentiate the formation of PDX through a double oxygenation mechanism [106] from the formation of PD1 which requires a transient epoxidation after the lipoxygenation, followed by the water-dependent epoxide opening.

4-hydroxy-alkenals can be quantified directly through HPLC with UV detection at 220 $\mathrm{nm}$ [162-164] or after derivatization with 2,4dinitrophenylhydrazine (DNPH) at $340 \mathrm{~nm}$ 
[165]. They can also be detected with a higher sensitivity by NICl GC-MS after derivatization using O-pentafluorobenzyl hydroxylamine hydrochloride for the carbonyl group, and N,O-bis trimethylsilyltrifluoroacetamide for the hydroxyl group [166-172].Their corresponding deuterated hydroxyalkenals are used for quantitation (Fig. 6). NKs adducts are detected and quantified by LC/ESI/MS/MS in the positive ion mode as described $[145,148,149,150,173]$. The basis of the method for quantifying NK-proteins adducts involves enzymatic digestion of proteins to individual amino acids followed by analysis of lysyl-NK adducts.

\section{Conclusion}

Omega-3 PUFA might play an important role in preventing atherothrombosis by themselves and through their oxygenated metabolites. However, it is obvious that the molecular mechanism explaining these effects on cardiovascular risk factors remain partially unclear, and further research needs to be launched. It seems important to look at the effects of other omega-3 PUFA than the main ones (ALA, EPA and DHA), such as docosapentaenoic acid and the very long-chain omega-3 PUFA (C24 and above), to search for new bioactive oxygenated metabolites.

\section{Acknowledgements}

The support of Inserm and INRA, the French Ministry of Higher Education and Research, the LISA Carnot Institute and the IBiSA Functional Lipidomics platform is greatly acknowledged.

\section{Abbreviations}

ARA, arachidonic acid; ALA, alpha-linolenic acid; COX, cyclooxygenase; DHA, docosahexaenoic acid; DPA, docosapentaenoic acid; EPA, eicosapentaenoic acid; ETA, 8,11,14,17-eicosatetraenoic acid; HDDE, 4-hydroxy-dodecadienal; HDL, high- 
density lipoproteins; 12-HETE, 12-hydroxy-eicosatetraenoic acid; HHE, hydroxyhexenal; HNE, hydroxy-nonenal; 12-HpETE, 12-hydroperoxy-eicosatetraenoic acid; HODE, hydroxy-octadecadienoic acid; HPLC, high-performance liquid chromatography; IsoK, isoketal; IsoP, isoprostane; LDL, low-density lipoproteins; LOX, lipoxygenase; MDA, malondialdehyde; NK, neuroketal; NP, neuroprostane; PD, protectin D; PG, prostaglandins; PGHS, prostaglandin $\mathrm{H}$ synthase; $\mathrm{PGH}_{2}$, prostaglandin $\mathrm{H}_{2} ; \mathrm{PGl}_{2}$, prostacyclin; PUFA, polyunsaturated fatty acids; ROS, reactive oxygen species; RvD, resolvin $\mathrm{D}$; RvE, resolvin $\mathrm{E}$; SDA, stearidonic acid; TAG, triacylglycerols; Tx, thromboxane; VLDL, very low-density lipoproteins.

\section{Figure legends}

Figure 1: Biogenesis of long-chain polyunsaturated fatty acids (PUFA) from the essential fatty acids in mammals, linoleic $(18: 2 \omega 6)$ and alpha-linolenic $(18: 3 \omega 3)$ acids. The whole sequence mainly occurs in the endoplasmic reticulum, except for shortening the 24-carbon intermediates by beta-oxidation ( $\beta$-ox) which occurs in peroxisomes.

$\Delta$ and $\mathrm{E}$ represent desaturases and elongases, respectively.

Figure 2: Selected oxygenation pathways related to the three main omega-3 PUFA (ALA, EPA and DHA) discussed in the review, with some pathways regarding ARA as a reference PUFA. Apart from the cyclooxygenase (COX) activities involved in the conversion of EPA into prostanoids of the three series (as largely described for ARA that is converted into prostanoids of the two series), the three omega-3 PUFA are mainly oxygenated by lipoxygenases (LOX). "LOX" means that several LOX and/or LOX plus other oxygenation pathways may be involved.

COX: cyclooxygenase; Epox/Hydr: epoxidase + hydrolase; GPx: glutathione peroxidase.

Hp/HEPE: hydroperoxy/hydroxy-eicosapentaenoate; Hp/HETE: hydroperoxy/hydroxy-eicosatetraenoate; Hp/HDoHE: hydroperoxy/hydroxy- 
docosahexaenoate; Hp/HOTE: hydroperoxy/hydroxy-octadecatrienoate; LT: leukotriene; PG: prostaglandin; Tx: thromboxane.

anti-aggregatory:

pro-aggregatory :

Figure 3: Dehydration of $P G D_{2}$ and $D_{3}$ into $P G J_{2}$ and $J_{3}$, then into $15 d P J_{2}$ and $J_{3}$. The former are activator of adenylyl cyclase, and the latter are ligands of peroxisome proliferator-activating receptor gamma.

Figure 4: Three poxytrins (Pufa OXYgenated TRlenes), characterized by an E,Z,E conjugated triene. Linotrin, LTBX and PDX derive from the double lipoxygenation of ALA, ARA and DHA, respectively. LTBX and PDX are stereochemical and geometric isomers of $\mathrm{LTB}_{4}$ [5(S),12(R)-dihydroxy-6Z,8E,10E-20:4] and PD1 [10(R),17(S)dihydroxy-11E,13Z,15E-22:6], respectively.

Figure 5: Structures of the two hydroxy-alkenals 4-HNE and 4-HHE from omega-6 and -3 PUFA, respectively, and their dehydrogenated oxo derivatives.

The structure of a major neuroketal from DHA is also shown.

Figure 6: $\mathrm{NICl}$ gas-chromatography/mass spectrometry tracing of $150 \mathrm{pg}$ of derivatized 4-HHE and 4-HNE. Each of them show the syn and anti isomers.

\section{References}

[1] Lozano R, Naghavi M, Foreman K, Lim S, Shibuya K, Aboyans V, Abraham J, Adair $\mathrm{T}$, et al. Global and regional mortality from 235 causes of death for 20 age groups in 1990 and 2010: a systematic analysis for the Global Burden of Disease Study 2010. Lancet. 2012;380:2095-2128. 
[2] Page IH, Allen EV, Chamberlain FL, Keys A, Stamler J, Stare FJ. Dietary fat ant its relation to heart attacks and strokes. Circulation. 1961;23:133-136.

[3] Bang HO, Dyerberg J. Plasma lipids and lipoproteins in Greenlandic west coast Eskimos. Acta Med Scand. 1972;192:85-94.

[4] Dyerberg J, Bang HO. Lipid metabolism, atherogenesis, and haemostasis in Eskimos: the role of the prostaglandin-3 family. Haemostasis. 1979;8:227-233.

[5] Kromhout D, Bosschieter EB, de Lezenne Coulander C. The inverse relation between fish consumption and 20 -year mortality from coronary heart disease. $\mathrm{N}$ Engl J Med. 1985;312:1205-1209.

[6] Gruppo Italiano per lo Studio della Sopravvivenza nell'Infarto miocardico. Dietary supplementation with n-3 polyunsaturated fatty acids and vitamin $\mathrm{E}$ after myocardial infarction: results of the GISSI-Prevenzione trial. Lancet. 1999;354:447-455.

[7] von Schacky C, Weber PC. Metabolism and effects on platelet function of the purified eicosapentaenoic and docosahexaenoic acids in Humans. J Clin Invest. 1985;76:2446-2450.

[8] Din JN, Newby DE, Flapan AD. Omega 3 fatty acids and cardiovascular diseasefishing for a natural treatment. BMJ. 2004;328:30-35.

[9 Kwak SM, Myung SK, Lee YJ, Seo HG. Korean Meta-analysis Study Group, Efficacyof omega-3 fatty acid supplements (eicosapentaenoic acid and 
docosahexaenoic acid) in the secondary prevention of cardiovascular disease: a meta-analysis of randomized, double-blind, placebo-controlled trials, Arch. Intern. Med. 172 (2012) 686-694.

[10] Rizos EC, Ntzani EE, Bika E, Kostapanos MS, Elisaf MS. Association between omega-3 fatty acid supplementation and risk of major cardiovascular disease events: a systematic review and meta-analysis. JAMA. 2012;308:1024-1033.

[11] Messori A, Fadda V, Maratea D, Trippoli S. $\omega-3$ fatty acids supplements for secondary prevention of cardiovascular disease: from "no proof of effectiveness" to "Proof of no effectiveness". JAMA Intern Med, 2013;173:1466-1468.

[12] Grey A, Bolland M. Clinical trial evidence and use of fish oil supplements. JAMA Intern Med, 2014;460-462.

[13] Rauch B, Schiele R, Schneider S, Diller F, Victor N, Gohlke H, Gottwik M, Steinbeck G, Del Castillo U, Sack R, Worth H, Katus H, Spitzer W, Sabin G, Senges J; OMEGA Study Group. Circulation, 2010;122:2152-2159.

[14] Kromhout D, Giltay EJ, Geleijnse JM; Alpha Omega Trial Group n-3 fatty acids and cardiovascular events after myocardial infarction. N Engl J Med. 2010;363:20152026.

[15] von Schacky C. Omega-3 fatty acids in cardiovascular disease - An uphill battle. Prostaglandins Leukot Essent Fatty Acids. 2014 May 28. pii: S0952-3278(14)000799. Doi. 10.1016. 
[16] de Oliveira Otto MC, Wu JHY, Baylin A, Vaidya D, Rich SS, Tsai MY, Jacobs DR Mozaffarian D. Circulating and dietary omega-3 and omega-6 polyunsaturated fatty acids and incidence of CVD in the Multi-Ethnic study of atherosclerosis. J Am Heart Assoc. 2013;2:e000506.

[17] Brouwer IA, Katan MB, Zock PL. Dietary alpha-linolenic acid is associated with reduced risk of fatal coronary heart disease, but increased prostate cancer risk: a meta-analysis. J Nutr. 2004;134:919-922.

[18] Pan A, Chen M, Chowdhury R, Wu JH, Sun Q, Campos H, Mozaffarian D, Hu FB. a-Linolenic acid and risk of cardiovascular disease: a systematic review and meta-analysis. Am J Clin Nutr. 2012;96:1262-1273.

[19] Holy EW, Forestier M, Richter EK, Akhmedov A, Leiber F, Camici GG, Mocharla $\mathrm{P}$, Luscher TF, Beer JH, Tanner FC. Dietary alpha-linolenic acid inhibits arterial thrombus formation, tissue factor expression, and platelet activation. Arterioscler Thromb Vasc Biol. 2011;31:1772-1780.

[20] Rallidis LS, Paschos G, Liakos GK, Velissaridou AH, Anastasiadis G,Zampelas A. Dietary alpha-linolenic acid decreases c-reactive protein, serum amyloid a and interleukin-6 in dyslipidaemic patients. Atherosclerosis. 2003;167:237-242.

[21] Burdge GC, Calder PC. Dietary alpha-linolenic acid and health-related outcomes: a metabolic perspective. Nutr Res Rev. 2006;19:26-52.

[22] Egert S, Kannenberg F, Somoza V, Erbersdobler HF, Wahrburg U. Dietary alpha-linolenic acid, EPA, and DHA have differential effects on LDL fatty acid 
composition but similar effects on serum lipid profiles in normolipidemic humans. $J$ Nutr. 2009;139:861-868.

[23] Brenna JT. Efficiency of conversion of alpha-linolenic acid to long chain n-3 fatty acids in man. Curr Opin Clin Nutr Metab Care. 2002;5:127-132.

[24] Brenna JT, Salem N Jr, Sinclair AJ, Cunnane SC. alpha-Linolenic acid supplementation and conversion to n-3 long-chain polyunsaturated fatty acids in humans. Prostaglandins Leukot Essent Fatty Acids. 2009;80:85-91.

[25] Liu M, Chen P, Véricel E, Lelli $M$, Béguin L, Lagarde $M$, Guichardant $M$. Characterization and biological effects of di-hydroxylated compounds deriving from the lipoxygenation of ALA. J Lipid Res. 2013,54:2083-2094.

[26] Wahl HG, Kausch C, Machicao F, Rett K, Stumvoll M, Häring HU. Troglitazone downregulates delta- 6 desaturase gene expression in human skeletal muscle cell cultures. Diabetes. 2002;5:1060-1065.

[27] James MJ, Ursin VM, Cleland LG. Metabolism of stearidonic acid in human subjects: comparison with the metabolism of other $n-3$ fatty acids. Am J Clin Nutr. 2003;77:1140-1145.

[28] Surette ME. Dietary omega-3 PUFA and health: stearidonic acid-containing seed oils as effective and sustainable alternatives to traditional marine oils. Mol Nutr Food Res. 2013;57:748-759. 
[29] Kockmann V, Spielmann D, Traitler H, Lagarde M. Inhibitory effect of stearidonic acid (18:4 n-3) on platelet aggregation and arachidonate oxygenation. Lipids. 1989;24:1004-1007.

[30] Surette ME, Edens M, Chilton FH, Tramposch KM. Dietary echium oil increases plasma and neutrophil longchain (n-3) fatty acids and lowers serum triacylglycerols in hypertriglyceridemic humans. J Nutr. 2004;134,1406-1411.

[31] Miles EA, Banerjee T, Calder, PC. The influence of different combinations of gamma-linolenic, stearidonic and eicosapentaenoic acids on the fatty acid composition of blood lipids and mononuclear cells in human volunteers. Prostagland Leukot Essent Fatty Acids. 2004;70:529-538.

[32] Lemke, S.L, Vicini, JL, Su, H, Goldstein, DA, Nemeth MA, Krul ES, Harris WS. Dietary intake of stearidonic acid-enriched soybean oil increases the omega-3 index: randomized, double-blind clinical study of efficacy and safety. Am J Clin Nutr. 2010; 92:766-775.

[33] Harris W.S, Lemke S.L, Hansen SN, Goldstein DA, DiRienzo MA, Su H, Nemeth MA, Taylor ML, Ahmed G, George C. Stearidonic acid-enriched soybean oil increased the omega-3 index, an emerging cardiovascular risk marker. Lipids. 2008, 43:805-811.

[34] Croset M, Bordet JC, Lagarde M. Inhibition of prostaglandin $\mathrm{H}$ synthase and activation of 12-lipoxygenase by 8,11,14,17-eicosatetraenoic acid in human endothelial cells and platelets. Biochem Pharmacol. 1999;57:631-638. 
[35] Harris WS. N-3 fatty acids and serum lipoproteins: human studies. Am J Clin Nutr. 1997;65:1645S-1654S.

[36] Kelley DS, Siegel D, Vemuri M, Mackey BE. Docosahexaenoic acid supplementation improves fasting and postprandial lipid profiles in hypertriglyceridemic men. Am J Clin Nutr. 2007;86:324-333.

[37] Balk EM, Lichtenstein AH, Chung M, Kupelnick B, Chew P, Lau J. Effects of omega-3 fatty acids on serum markers of cardiovascular disease risk: a systematic review. Atherosclerosis. 2006;189:19-30.

[38] Harris WS, Hustvedt BE, Hagen E, Green MH, Drevon CA. Very long-chain omega-3 fatty acids enhance chylomicron clearance in the rat. J Lipid Res. 1997; 38:503-515.

[39] Harris WS, Miller M, Tighe AP, Davidson MH, Schaefer EJ. Omega-3 fatty acids and coronary heart disease risk: clinical and mechanistic perspectives. Atherosclerosis. 2008;197:12-24.

[40] Kanji S, Seely D, Yazdi F, Tetzlaff J, Singh K, Tsertsvadze A, Tricco AC, Sears ME, Ooi TC, Turek MA, Skidmore B, Ansari MT. Interactions of commonly used dietary supplements with cardiovascular drugs: a systematic review. Syst Rev. 2012;1:26-41.

[41] Howe PR, Lungershausen YK, Cobiac L, Dandy G, Nestel PJ. Effect of sodium restriction and fish oil supplementation on $\mathrm{BP}$ and thrombotic risk factors in patients treated with ACE inhibitors. J Hum Hypertens. 1994;8:43-49. 
[42] Schmidt EB, Kristensen SD, De Caterina R, Illingworth DR. The effects of $n-3$ fatty acids on plasma lipids and lipoproteins and other cardiovascular risk factors in patients with hyperlipidemia. Atherosclerosis. 1993;103:107-121.

[43] Minihane AM, Khan S, Leigh-Firbank EC, Talmud P, Wright JW, Murphy MC, Griffin BA, Williams CM. ApoE polymorphism and fish oil supplementation in subjects with an atherogenic lipoprotein phenotype. Arterioscler Thromb Vasc Biol. 2000;20:1990-1997.

[44] Caslake MJ, Miles EA, Kofler BM, Lietz G, Curtis P, Armah CK, Kimber AC, Grew JP, Farrell L, Stannard J, Napper FL, Sala-Vila A, West AL, Mathers JC, Packard C, Williams CM, Calder PC, Minihane AM. Effect of sex and genotype on cardiovascular biomarker response to fish oils: the FINGEN Study. Am J Clin Nutr. 2008;88:618-629.

[45] Mori TA, Burke V, Puddey IB, Watts GF, O'Neal DN, Best JD, Beilin LJ. Purified eicosapentaenoic and docosahexaenoic acids have differential effects on serum lipids and lipoproteins, LDL particle size, glucose, and insulin in mildly hyperlipidemic men. Am J Clin Nutr. 2000;71:1085-1094.

[46] Suzukawa M, Abbey M, Howe PR, Nestel PJ. Effects of fish oil fatty acids on low density lipoprotein size, oxidizability, and uptake by macrophages. J Lipid Res. 1995;36:473-484.

[47] Woodman RJ, Mori TA, Burke V, Puddey IB, Watts GF, Best JD, Beilin LJ. Docosahexaenoic acid but not eicosapentaenoic acid increases LDL particle size in treated hypertensive type 2 diabetic patients. Diabetes Care. 2003;26:253. 
[48] Mori TA, Vandongen R, Beilin LJ, Burke V, Morris J, Ritchie J. Effects of varying dietary fat, fish, and fish oils on blood lipids in a randomized controlled trial in men at risk of heart disease. Am J Clin Nutr. 1994;59:1060-1068.

[49] Abbey M, Clifton P, Kestin M, Belling B, Nestel P. Effect of fish oil on lipoproteins, lecithin:cholesterol acyltransferase, and lipid transfer protein activity in humans. Arteriosclerosis. 1990;10:85-94.

[50] Bang HO, Dyerberg J, Hjorne N. The composition of food consumed by Greenland Eskimos. Acta Med Scand. 1976;200:69-73.

[51] Bang HO, Dyerberg J,Nielsen AB. Plasma lipid and lipoprotein pattern in Greenlandic West-coast Eskimos. Lancet 1971;1:1143-1145.

[52] Kaplan ZS, Jackson SP. The role of platelets in atherothrombosis. Hematology. 2011;1:51-61.

[53] Massberg S, Brand K, Gruner S,Page S, Muller E, Muller I, Bergmeier W, Richter T, Lorenz M, Konrad I, Nieswandt B, Gawaz M. A critical role of platelet adhesion in the initiation of atherosclerotic lesion formation. J Exp Med. 2002;196:887-896.

[54] Dyerberg J, Bang HO. Haemostatic function and platelet polyunsaturated fatty acids in Eskimos. Lancet 1975;2:433-435. 
[55] Nelson GJ, Schmidt PC, Bartolini G, Kelley DS, Kyle D. The effect of dietary arachidonic acid on platelet function, platelet fatty acid composition, and blood coagulation in humans. Lipids. 1997;32:421-425.

[56] Goodnight SH Jr, Harris WS, Connor WE, Illingworth DR. Polyunsaturated fatty acids, hyperlipidemia, and thrombosis. Arteriosclerosis. 1982;2:87-113.

[57] Siess W, Roth P, Scherer B, Kurzmann I, Böhlig B, Weber PC. Plateletmembrane fatty acids, platelet aggregation, and thromboxane formation during a mackerel diet. Lancet. 1980;1:441-444.

[58] Prisco D, Filippini M, Francalanci I, Paniccia R, Gensini GF, Serneri GG. Effect of $n-3$ fatty ethyl ester supplementation on fatty acid composition of the single platelet phospholipids and on platelet functions. Metabolism. 1995;44,562-569.

[59] Phang M, Lincz LF, Garg ML. Eicosapentaenoic and docosahexaenoic acid supplementations reduce platelet aggregation and hemostatic markers differentially in men and women. J Nutr. 2013;143:457-463.

[60] Véricel E, Calzada C, Chapuy P, Lagarde M. The influence of low intake of n-3 fatty acids on platelets in elderly people. Atherosclerosis. 1999;147:187-192.

[61] McEwen BJ, Morel-Kopp MC, Chen W, Tofler GH, Ward CM. Effects of omega-3 polyunsaturated fatty acids on platelet function in healthy subjects with cardiovascular disease. Semin Thromb Haemost. 2013;39:25-32. 
[62] Hooper L, Thompson RL, Harrison RA, Summerbell CD, Moore H, Worthington HV, Durrington PN, Ness AR, Capps NE, Davey Smith G, Riemersma RA, Ebrahim SB. Omega 3 fatty acids for prevention and treatment of cardiovascular disease. Cochrane Database Syst Rev. 2004;18:CD003177.

[63] Gao LG, Cao J, Mao QX, Lu XC, Zhou XL, Fan L. Influence of omega-3 polyunsaturated fatty acid-supplementation on platelet aggregation in humans: a meta-analysis of randomized controlled trials. Atherosclerosis. 2013;226:328-334.

[64] Driss F, Véricel E, Lagarde M, Dechavanne M, Darcet Ph. Inhibition of platelet aggregation and thromboxane synthsesis after intake of small amount of icosapentaenoic acid. Thromb Res. 1984;36:389-396.

[65] Croset M., Véricel E, Rigaud M, Hanss $M$, Courpron Ph, Dechavanne $M$, Lagarde M. Functions and tocopherol content of blood platelets from elderly people after low intake of purified eicosapentaenoic acid. Thromb Res. 1990;57:1-12.

[66] Brossard N, Croset M, Pachiaudi C, Riou JP, Tayot JL, Lagarde M. Retroconversion and metabolism of [13C]22:6n-3 in humans and rats after intake of a single dose of [13C]22:6n-3-triacylglycerols. Am J Clin Nutr. 1996;64:577-586.

[67] Guillot N, Caillet E, Laville M, Calzada C, Lagarde M, Véricel E. Increasing intakes of the long chain omega-3 docosahexaenoic acid: effects on platelet functions and redox status in healthy men. FASEB J. 2009;23:2909-2916.

[68] Conquer JA, Holub BJ. Supplementation with an algae source of docosahexaenoic acid increases (n-3) fatty acid status and alters selected risk factors for heart disease in vegetarian subjects. J Nutr. 1996;126:3032-3039. 
[69] Akiba S, Murata T, Kitatani K, Sato T. Involvement of lipoxygenase pathway in docosapentaenoic acid-induced inhibition of platelet aggregation. Biol Pharm Bull. 2000;23:1293-1297.

[70] Lagarde M. Metabolism of fatty acids by platelets and the functions of various metabolites in mediating platelet function. Prog Lipid Res. 1988;27:135-152.

[71] Fisher S, Weber PC. Thromboxane (TX)A3 is formed in human platelets after dietary eicosapentaenoic acid (20:5n-3). Biochem Biophys Res Commun. 1983;116: 1091-1099.

[72] Fisher S, Weber PC. Thromboxane (TX)A3 and prostaglandin (PG)|3 are formed in man after dietary eicosapentaenoic acid: identification and quantification by capillary gas chromatography-electron impact mass spectrometry. Biomed Mass Spectrom. 1985;12:470-476.

[73] Jung UJ, Torrejon C, Tighe AP, Deckelbaum RJ. N-3 Fatty acids and cardiovascular disease: mechanisms underlying beneficial effects. Am J Clin Nutr. 2008;87:2003S-2009S.

[74] Samuelsson B. Prostaglandin endoperoxides and thromboxanes: role in platelets and in vascular and respiratory smooth muscle. Acta Biol Med Ger. 1976;35:10551063. 
[75] Boukhchache D, Lagarde M. Interactions between prostaglandin precursors during their oxygenation by human platelets. Biochim Biophys Acta. 1982;713:386392.

[76] Swann PG, Parent CA, Croset M, Fonlupt P, Lagarde M, Venton DL, Le Breton GC. Enrichment of platelet phospholipids with eicosapentaenoic acid and docosahexaenoic acid inhibits thromboxane A2/prostaglandin $\mathrm{H} 2$ receptor binding and function. J Biol Chem. 1990;265:21692-21697.

[77] Smith WL, Urade Y, Jakobsson PJ. Enzymes of the cyclooxygenase pathways of prostanoid biosynthesis. Chem Rev. 2011;111:5821-5865.

[78] Larson MK, Ashmore JH, Harris KA, Vogelaar JL, Pottala JV, Sprehe M, Harris WS. Effects of omega-3 acid ethyl esters and aspirin, alone and in combination, on platelet function in healthy subjects. Thromb Haemost. 2008;100:634-641.

[79] Lev El, Solodky A, Harel A, Mager A, Brosh D, Assali A, Roller M, Battler A., Kleiman NS, Kornowski R. Treatment of aspirin-resistant patients with omega-3 fatty acids versus aspirin dose escalation. J Am Coll Cardiol. 2010;55:114-121.

[80] Gajos G, Rostoff P, Undas A, Piwowarska W. Effects of polyunsaturated omega3 fatty acids on responsiveness to dual antiplatelet therapy in patients undergoing percutaneous coronary intervention: the OMEGA-PCI (OMEGA-3 fatty acids after pci to modify responsiveness to dual antiplatelet therapy) study. J Am Coll Cardiol. 2010;55:1671-168.

[81] Shahar E1, Folsom AR, Wu KK, Dennis BH, Shimakawa T, Conlan MG, Davis $\mathrm{CE}$, Williams OD. Associations of fish intake and dietary n-3 polyunsaturated fatty 
acids with a hypocoagulable profile. The Atherosclerosis Risk in Communities (ARIC) Study. Arterioscler Thromb. 1993;13:1205-1212.

[82] Gajos G, Zalewski J, Rostoff P, Nessler J, Piwowarska W, Undas A. Reduced thrombin formation and altered fibrin clot properties induced by polyunsaturated omega-3 fatty acids on top of dual antiplatelet therapy in patients undergoing percutaneous coronary intervention (OMEGA-PCl clot). Arterioscler Thromb Vasc Biol. 2011;31:1696-1702.

[83] Kaur G, Cameron-Smith D, Garg M, Sinclair AJ. Docosapentaenoic acid (22:5n3): a review of its biological effects. Prog Lipid Res. 2011;50:28-34.

[84] Hishinuma T, Yamazaki T, Mizugaki M. Effects of long-term supplementation of eicosapentanoic and docosahexanoic acid on the 2-, 3-series prostacyclin production by endothelial cells. Prostaglandins Other Lipid Mediat. 1999;57:333-340.

[85] Bénistant C, Achard F, Ben Salma S, Lagarde M. Docosapentaenoic acid (22:5n-3): metabolism and effect on prostacyclin production in endothelial cells. Prostaglandins Leukot Essent Fatty Acids. 1996;55:287-292.

[86] Fischer R, Konkel A, Mehling H, Blossey K, Gapelyuk A, Wessel N, von Schacky C, Dechend R, Muller DN, Rothe M, Luft FC, Weylandt K, Schunck WH. Dietary omega-3 fatty acids modulate the eicosanoid profile in man primarily via the CYPepoxygenase pathway. J Lipid Res. 2014 (in press).

[87] Arnold C, Markovic M, Blossey K, Wallukat G, Fischer R, Dechend R, Konkel A, von Schacky C, Luft FC, Muller DN, Rothe M, Schunck WH. Arachidonic acid- 
metabolizing cytochrome P450 enzymes are targets of omega-3 fatty acids. J Biol Chem. 2010;285:32720-32733.

[88] Hersberger M. Potential role of the lipoxygenase derived lipid mediators in atherosclerosis: leukotrienes, lipoxins and resolvins. Clin Chem Lab Med. 2010;48:1063-1073.

[89] Serhan CN, Clish CB, Brannon J, Colgan SP, Chiang N, Gronert K. Novel functional sets of lipid-derived mediators with antiinflammatory actions generated from omega-3 fatty acids via cyclooxygenase 2-nonsteroidal antiinflammatory drugs and transcellular processing. J Exp Med. 2000;192:1197-1204.

[90] Arita M, Bianchini F, Aliberti J, Sher A, Chiang N, Hong S, Yang R, Petasis NA, Serhan CN. Stereochemical assignment, antiinflammatory properties, and receptor for the omega-3 lipid mediator resolvin E1. J Exp Med. 2005;201:713-722.

[91] Spite M, Serhan CN. Novel lipid mediators promote resolution of acute inflammation: impact of aspirin and statins. Circ Res. 2010;107:1170-1184.

[92] Dona M, Fredman G, Schwab JM, Chiang N, Arita M, Goodarzi A, Cheung G, von Andrian UH, Serhan CN. Resolvin E1, an EPA-derived mediator in whole blood, selectively counterregulates leukocytes ans platelets. Blood. 2008;112:3848-3855.

[93] Needleman P, Minkes M, Raz A. Thromboxanes: selective biosynthesis and distinct biological properties. Science. 1976;193:163-165. 
[94] Needleman P, Raz A, Minkes MS, Ferrendelli JA, Sprecher H. Triene prostaglandins: prostacyclin and thromboxane biosynthesis and unique biological properties. Proc Natl Acad Sci USA. 1979;76:944-948.

[95] Yerram NR, Moore SA, Spector AA. Eicosapentaenoic acid metabolism in brain microvessel endothelium: effect on prostaglandin formation. J Lipid Res. 1989;30:1747-1757.

[96] Hegde S, Kaushal N, Ravindra KC, Chiaro C, Hafer KT, et al. $\Delta 12$-prostaglandin J3, an omega-3 fatty acid-derived metabolite, selectively ablates leukemia stem cells in mice. Blood. 2011;118:6909-6919.

[97] Lefils-Lacourtablaise J, Socorro M, Géloën A, Daira P, Debard C, Loizon E, Guichardant M, Dominguez Z, Vidal H, Lagarde M, Bernoud-Hubac N. The eicosapentaenoic acid metabolite 15-deoxy- $\delta(12,14)$-prostaglandin $J 3$ increases adiponectin secretion by adipocytes partly via a PPARy-dependent mechanism. PLoS One. 2013;85:e63997.

[98] Whitaker MO, Wyche A, Fitzpatrick F, Sprecher H, Needleman P. Triene prostaglandins: prostaglandin D3 and icosapentaenoic acid as potential antithrombotic substances. Proc Natl Acad Sci U S A.1979;76:5919-5923.

[99] Juan H, Sametz W. Dihomo-gamma-linolenic acid increases the metabolism of eicosapentaenoic acid in perfused vascular tissue. Prostaglandins Leukot Med. 1985;19:79-86.

[100] Hawkes JS, James MJ, Cleland LG. Biological activity of prostaglandin E3 with regard to oedema formation in mice. Agents Actions. 1992;35:85-87. 
[101] Tull SP, Yates CM, Maskrey BH, O'Donnell VB, Madden J, Grimble RF, Calder PC, Nash GB, Rainger GE. Omega-3 Fatty acids and inflammation: novel interactions reveal a new step in neutrophil recruitment. PLoS Biol. 2009;7:e1000177.

[102] Calder PC. Polyunsaturated fatty acids and inflammatory processes: New twists in an old tale. Biochimie. 2009;91:791-795.

[103] Croset M, Sala A, Folco G, Lagarde M. Inhibition by lipoxygenase products of TXA2-like responses of platelets and vascular smooth muscle. 14-Hydroxy from 22:6n-3 is more potent than 12-HETE. Biochem Pharmacol. 1988;37:1275-1280.

[104] Fonlupt $P$, Croset M, Lagarde M.12-HETE inhibits the binding of PGH2/TXA2 receptor ligands in human platelets. Thromb Res. 1991;63:239-248.

[105] Merched AJ, Ko K, Gotlinger KH, Serhan CN, Chan L. Atherosclerosis: evidence for impairment of resolution of vascular inflammation governed by specific lipid mediators. FASEB J. 2008;22:3595-35606.

[106] Chen P, Fenet B, Michaud S, Tomczyk N, Véricel E, Lagarde M, Guichardant M. Full characterization of PDX, a neuroprotectin/protectin D1 isomer, which inhibits blood platelet aggregation. FEBS Lett. 2009;583:3478-3484.

[107] Chen P, Véricel E, Lagarde M, Guichardant M. Poxytrins, a class of oxygenated products from polyunsaturated fatty acids, potently inhibit blood platelet aggregation. FASEB J. 2011;25:382-388. 
[108] Liu M, Boussetta T, Makni-Maalej K, Fay M, Driss F, El-Benna J, Lagarde M, Guichardant M.Protectin DX, a double lipoxygenase product of DHA, inhibits both ROS production in human neutrophils and cyclooxygenase activities. Lipids. 2014;49:49-57.

[109] Balas L, Guichardant M, Durand T, Lagarde M. Confusion between protectin D1 (PD1) and its isomer protectin DX (PDX). An overview on the dihydroxydocosatrienes described to date. Biochimie. 2014;99:1-7.

[110] Lu Y, Tian H, Hong S. Novel 14,21-dihydroxy-docosahexaenoic Acids: Structures, Formation Pathways, and Enhancement of Wound Healing J Lipid Res. 2010;51:923-932.

[111] Yagi K. Lipid peroxides and human diseases. Chem Phys Lipids. 1987;45:337351.

[112] Brown JE, Wahle KWJ. Effect of fish oil and vitamin E supplementation on lipid peroxidation and whole blood aggregation in man. Clin Chim Acta. 1990;193:147156.

[113] Nair PP, Judd JT, Berlin E, Taylor PR, Shami S, Sainz E, Bhagavan HN. Dietary fish oil-induced changes in the distribution of alpha-tocopherol, retinol, and beta-carotene in plasma, red blood cells, and platelets: modulation by vitamin E. Am. J Clin Nutr. 1993;58:98-102. 
[114] Harats D, Dabach Y, Ben-Naim M, Schwartz R, Berry EM, Stein O, Stein Y. Fish oil ingestion in smokers and nonsmokers enhances peroxidation of plasma lipoproteins. Atherosclerosis. 1991;90:127-139.

[115] Brude IR, Drevon CA, Hjermann I, et al. Peroxidation of LDL from combinedhyperlipidemic male smokers supplied with omega-3 fatty acids and antioxidants. Arterioscler Thromb Vasc Biol. 1997;17:2576-2588.

[116] Polette A, Lemaitre D, Lagarde M, Véricel E. N-3 fatty acid-induced lipid peroxidation in human platelets is prevented by catechins. Thromb Haemost. 1996;75:945-949.

[117] Lemaitre D, Véricel E, Polette A, Lagarde M. Effects of fatty acids on human platelet glutathione peroxidase : possible role of oxidative stress. Biochem Pharmacol. 1997;53:479-486.

[118] Véricel E, Polette A, Bacot S, Calzada C, Lagarde M.Pro- and antioxidant activities of docosahexaenoic acid on human blood platelets. J Thromb Haemost. 2003;1:566-572.

[119] Calzada C, Colas R, Guillot N, Guichardant M, Laville M, Véricel E, Lagarde M. Subgram daily supplementation with docosahexaenoic acid protects low-density lipoproteins from oxidation in healthy men. Atherosclerosis. 2010;208:467-472.

[120] Ishikado A, Morino K, Nishio Y, Nakagawa F, Mukose A, Sono Y, Yoshioka N, Kondo K, Sekine O, Yoshizaki T, Ugi S, Uzu T, Kawai H, Makino T, Okamura T, Yamamoto M, Kashiwagi A, Maegawa H. 4-Hydroxy hexenal derived from 
docosahexaenoic acid protects endothelial cells via Nrf2 activation. PLoS One. 2013; 8:e69415.

[121] Giordano E, Visioli F. Long-chain omega 3 fatty acids: molecular bases of potential antioxidant actions. Prostaglandins Leukot Essent Fatty Acids. 2014;90:1-4.

[122] Richard D, Wolf C, Barbe U, Kefi K, Bausero P, Visioli F. Docosahexaenoic acid down-regulates endothelial Nox4 through as PLA2 signaling pathway, Biochem. Biophys.Res.Commun. 2009,389:516-522.

[123] Mebarek S, Ermak N, Benzaria A, Vicca S, Dubois M, Némoz G, Laville M, Lacour B, Véricel E, Lagarde M, Prigent AF. Effects of increasing docosahexaenoic acid intake in human healthy volunteers on lymphocyte activation and monocyte apoptosis. Br J Nutr. 2009;1016:852-858.

[124] Mori TA, Dunstan DW, Burke V, Croft KD, Rivera JH, Beilin LJ, Puddey IB. Effect of dietary fish and exercise training on urinary F2-isoprostane excretion in noninsulin-dependent diabetic patients. Metabolism. 1999,48:1402-1408.

[125] Benedetti A, Comporti M, Fulceri R, Esterbauer H. Cytotoxic aldehydes originating from the peroxidation of liver microsomal lipids. Biochimica Biophysica Acta. 1980;620:281-286.

[126] Esterbauer H, Schaur RJ, Zollner H. Chemistry and biochemistry of 4hydroxynonenal, malondialdehyde and related aldehydes. Free Radic Biol Med. 1991;11:81-128. 
[127] Nadkarni DV, Sayre LM. Structural definition of early lysine and histidine adduction chemistry of 4-hydroxynonenal. Chem Res Toxicol. 1995;8:284-291.

[128] Jürgens G, Lang J, Esterbauer H. Modification of human low-density lipoprotein by the lipid peroxidation product 4-hydroxynonenal. Biochim Biophys Acta. 1986,875: 103-114.

[129] Lee SH, Blair IA. Characterization of 4-oxo-2-nonenal as a novel product of lipid peroxidation. Chem Res Toxicol. 2000;13:698-702.

[130] Lee SH, Oc T, Blair IA. Vitamin C-induced decomposition of lipid hydroperoxides to endogenous genotoxins. Science. 2001;292:2083-2086.

[131] Doorn JA, Petersen DR. Covalent adduction of nucleophilic amino acids by 4Hydroxynonenal anl and 4-oxononenal. Chem Biol Interaction. 2003;143:93-100.

[132] Esterbauer H, Jurgens G, Quehenberger $O$ and Koller E. Autoxidation of human low density lipoprotein: loss of polyunsaturated fatty acids and vitamin $E$ and generation of aldehydes. J Lipid Res. 1987;28:495-509.

[133] Steinbrecher UP. Oxidation of human low density lipoprotein results in derivatization of lysine residues of apolipoprotein $B$ by lipid peroxide decomposition products. J Biol Chem. 1987;262:3603-3608.

[134] Podrez EA, Hoppe G, O'Neil J, Sayre LM, Sheibani N and Hoff HF. Macrophage receptors responsible for distinct recognition of low density lipoprotein 
containing pyrrole or pyridinium adducts: models of oxidized low density lipoprotein. $J$ Lipid Res. 2000;41:1455-1463.

[135] Yamada S, Funada T, Shibata N, Kobayashi M, Kawai Y, Tatsuda E, Furuhata A, Uchida K. Protein-bound 4-hydroxy-2-hexenal as a marker of oxidized n-3 polyunsaturated fatty acids. J Lipid Res. 2004;45:626-634.

[136] Collot-Teixeira S, Martin J, McDermott-Roe C, Poston R, McGregor JL. CD36 and macrophages in atherosclerosis. Cardiovasc Res. 2007;75:468-477.

[137] Guichardant M, Taibi-Tronche P, Fay LB, Lagarde M. Covalent modifications of aminophospholipids by 4-hydroxynonenal. Free Radic Biol Med. 1998;25:1049-1056.

[138] Bacot S, Bernoud-Hubac N, Baddas N, Chantegrel B, Deshayes C, Doutheau A, Lagarde M, Guichardant M. Covalent binding of hydroxy-alkenals 4-HDDE, 4$\mathrm{HHE}$, and 4-HNE to ethanolamine phospholipid subclasses. J Lipid Res. 2003;44:917-926.

[139] Bacot S, Bernoud-Hubac N, Chantegrel B, Deshayes C, Doutheau A, Ponsin G, Lagarde M, Guichardant M. Evidence for in situ ethanolamine phospholipid adducts with hydroxy-alkenals. J Lipid Res. 2007;48:816-825.

[140] Hoff HF, O'Neil J, Wu Z, Hoppe G, Salomon RL. Phospholipid hydroxyalkenals: biological and chemical properties of specific oxidized lipids present in atherosclerotic lesions. Arterioscler Thromb Vasc Biol. 2003;23:275-282. 
[141] Salomon RG, Gu X. Critical Insights into cardiovascular disease from basic research on the oxidation of phospholipids: the 4-Hydroxyalkenal phospholipid hypothesis. Chem Res Toxicol. 2011;24:1791-1802.

[142] Ley K, Miller YI, Hedrick CC. ATVB in Focus: Vascular cell lineage determination and differentiation. Monocyte and macrophage dynamics during atherogenesis. Arterioscler Thromb Vasc Biol. 2011;31:1506-1516.

[143] Rahaman, SO, Lennon, DJ, Febbraio, M, Podrez, EA, Hazen, SL, Silverstein, $\mathrm{RL}$. A CD36-dependent signaling cascade is necessary for macrophage foam cell formation. Cell Metab. 2006;4:211-221.

[144] Brame CJ, Salomon RG, Morrow JD, Roberts LJ 2nd. Identification of extremely reactive gamma-ketoaldehydes (isolevuglandins) as products of the isoprostane pathway and characterization of their lysyl protein adducts. J Biol Chem. 1999;274:13139-13146.

[145] Bernoud-Hubac N, Davies SS, Boutaud O, Montine TJ, Roberts LJ 2nd. Formation of highly reactive gamma-ketoaldehydes (neuroketals) as products of the neuroprostane pathway. J Biol Chem. 2001;276:30964-30970.

[146] Bernoud-Hubac N, Roberts LJ 2nd. Identification of oxidized derivatives of neuroketals. Biochemistry. 2002;41:11466-11471.

[147] Guo L, Chen Z, Cox BE, Amarnath V, Epand RF, Epand RM, Davies SS. Phosphatidylethanolamines modified by $\mathrm{Y}$-ketoaldehyde ( $\mathrm{YKA}$ ) induce endoplasmic reticulum stress and endothelial activation. J Biol Chem. 2011;286:18170-18180. 
[148] Guo L, Chen Z, Amarnath V, Davies SS. Identification of novel bioactive aldehyde-modified phosphatidylethanolamines formed by lipid peroxidation. Free Radic Biol Med. 2012;53:1226-1238.

[149] Sullivan CB, Matafonova E, Roberts LJ 2nd, Amarnath V, Davies SS. Isoketals form cytotoxic phosphatidylethanolamine adducts in cells. J Lipid Res. 2010;51:9991009.

[150] Bernoud-Hubac N, Fay LB, Armarnath V, Guichardant M, Bacot S, Davies SS, Roberts LJ 2nd, Lagarde M. Covalent binding of isoketals to ethanolamine phospholipids. Free Radic Biol Med. 2004;37:1604-1611.

[151] Bernoud-Hubac N, Alam DA, Lefils J, Davies SS, Amarnath V, Guichardant M, Roberts LJ 2nd, Lagarde M. Low concentrations of reactive gamma-ketoaldehydes prime thromboxane-dependent human platelet aggregation via p38-MAPK activation. Biochim Biophys Acta. 2009;1791:307-313.

[152] Salomon RG, Batyreva E, Kaur K, Sprecher DL, Schreiber MJ, Crabb JW, Penn MS, DiCorletoe AM, Hazen SL, Podrez EA. Isolevuglandin-protein adducts in humans: products of free radical-induced lipid oxidation through the isoprostane pathway. Biochim Biophys Acta. 2000;1485:225-235.

[153] Stavrovskaya IG, Baranov SV, Guo X, Davies SS, Roberts LJ 2nd, Kristal BS. Reactive gamma-ketoaldehydes formed via the isoprostane pathway disrupt mitochondrial respiration and calcium homeostasis. Free Radic Biol Med. 2010;49:567-579. 
[154] Pratico D, Smyth EM, Violi F, FitzGerald GA. Local amplification of platelet function by 8-Epi prostaglandin F2alpha is not mediated by thromboxane receptor isoforms. J Biol Chem. 1996;271:4916-14924.

[155] Gao L, Yin H, Milne GL, Porter NA, Morrow JD. Formation of F-ring isoprostane-like compounds (F3-isoprostanes) in vivo from eicosapentaenoic acid. J Biol Chem. 2006;81:14092-14099.

[156] Roberts II LJ, Milne GL. Isoprostanes. J Lipid Res. 2009;50:S219-S223.

[157] Roberts LJ, Montine TJ, Markesbery WR, Tapper AR, Hardy P, Chemtob S, Dettbarn WD, Morrow JD. Formation of isoprostane-like compounds (neuroprostanes) in vivo from docosahexaenoic acid. J Biol Chem. 1998;273:360513612.

[158] Gladine C, Newman JW, Durand T, Pedersen TL, Galano J-M, Demougeot C, Berdeaux O, Pujos-Guillot E, Mazur A, Comte B. Lipid profiling following Intake of the omega 3 fatty acid DHA identifies the peroxidized metabolites F4-neuroprostanes as the best predictors of atherosclerosis prevention. PLoS ONE. 2014; 9:e89393.

[159] Strassburg K, Huijbrechts AM, Kortekaas KA, Lindeman JH, Pedersen TL, Dane A, Berger R, Brenkman A, Hankemeier T, van Duynhoven J, Kalkhoven E, Newman JW, Vreeken RJ. Quantitative profiling of oxylipins through comprehensive LC-MS/MS analysis: application in cardiac surgery. Anal Bioanal Chem. 2012;404:1413-1426.

[160] Le Faouder P, Baillif V, Spreadbury I, Motta JP, Rousset P, Chêne G, Guigné C, Tercé F, Vanner S, Vergnolle N, Bertrand-Michel J, Dubourdeau M, Cenac N. LC- 
MS/MS method for rapid and concomitant quantification of pro-inflammatory and proresolving polyunsaturated fatty acid metabolites. J Chromatogr B Analyt Technol Biomed Life Sci. 2013;932:123-133.

[161] Giera M, loan-Facsinay A, Toes R, Gao F, Dalli J, Deelder AM, Serhan CN, Mayboroda OA. Lipid and lipid mediator profiling of human synovial fluid in rheumatoid arthritis patients by means of LC-MS/MS. Biochim Biophys Acta. 2012;1821:1415-1424.

[162] Lang J, Celetto C, Esterbauer H. Quantitative determination of the lipid peroxidation product 4-hydroxynonenal by high-performance chromatography. Anal Biochem. 1985;150:369-378.

[163] Esterbauer H, Cheeseman KH. Determination of aldehydic lipid peroxidation products: malonaldehyde and 4-hydroxynonenal. Methods Enzymol. 1990;186:407421.

[164] Murphy TC, Amarnath V, Picklo MJ. Mitochondrial oxidation of 4-hydroxy-2nonenal in rat cerebral cortex. J. Neurochem. 2003;84:1313-1321.

[165] Cordis GA, Das DK, Riedel W. High-performance liquid chromatographic peak identification of 2,4-dinitrophenylhydrazine derivatives of lipid peroxidation aldehydes by photodiode array detection. J Chromatogr A. 1998;798:117-123.

[166] Van Kuijk FJ, Holte LL, Dratz EA. 4-Hydroxyhexenal: a lipid peroxidation product derived from oxidized docosahexaenoic acid. 1990;1043:116-118. 
[167] Kawai Y, Takeda S, Terao J. Lipidomic analysis for lipid peroxidation-derived aldehydes using gas chromatography-mass spectrometry. Chem Res Toxicol. 2007;20:99-107.

[168] Guichardant M, Chantegrel B, Deshayes C, Doutheau A, Molière P, Lagarde M. Specific markers of lipid peroxidation issued from n-3 and $n-6$ fatty acids. Biochem Soc Trans. 2004;32:139-140.

[169] Zarrouki B, Soares AF, Guichardant M, Lagarde M, Géloën A. The lipid peroxidation end-product 4-HNE induces COX-2 expression through p38MAPK activation in 3T3-L1 adipose cell. FEBS Lett. 2007;581:2394-2400.

[170] Long EK, Smoliakova I, Honzatko A, Picklo MJ. Structural characterization of alpha, beta-unsaturated aldehydes by gc/miss dependent upon ionization methods. Lipids 2008;43:765-774.

[171] Awada M, Soulage CO, Meynier A, Debard C, Plaisancié P, Benoit B, Picard G, Loizon E, Chauvin MA, Estienne M, Peretti N, Guichardant M, Lagarde M, Genot C, Michalski MC. Dietary oxidized n-3 PUFA induce oxidative stress and inflammation: role of intestinal absorption of 4-HHE and reactivity in intestinal cells. J Lipid Res. 2012;53:2069-2080.

[172] Wang M, Fang H, Han X. Shotgun lipidomics analysis of 4-hydroxyalkenal species directly from lipid extracts after one-step in situ derivatization. Anal Chem. 2012;84:4580-4586.

[173] Bernoud-Hubac N, Davies SS, Boutaud O, Roberts LJII. Analysis of Neuroketals Protein Adducts by Liquid Chromatography Electrospray Ionization 
Tandem Mass Spectrometry. In : Apoptosis Methods in Pharmacology and Toxicology: Methods in Biological Oxidative Stress (K. Hensley and R. A. Floyd, ed), 2003;pp 117-125. 


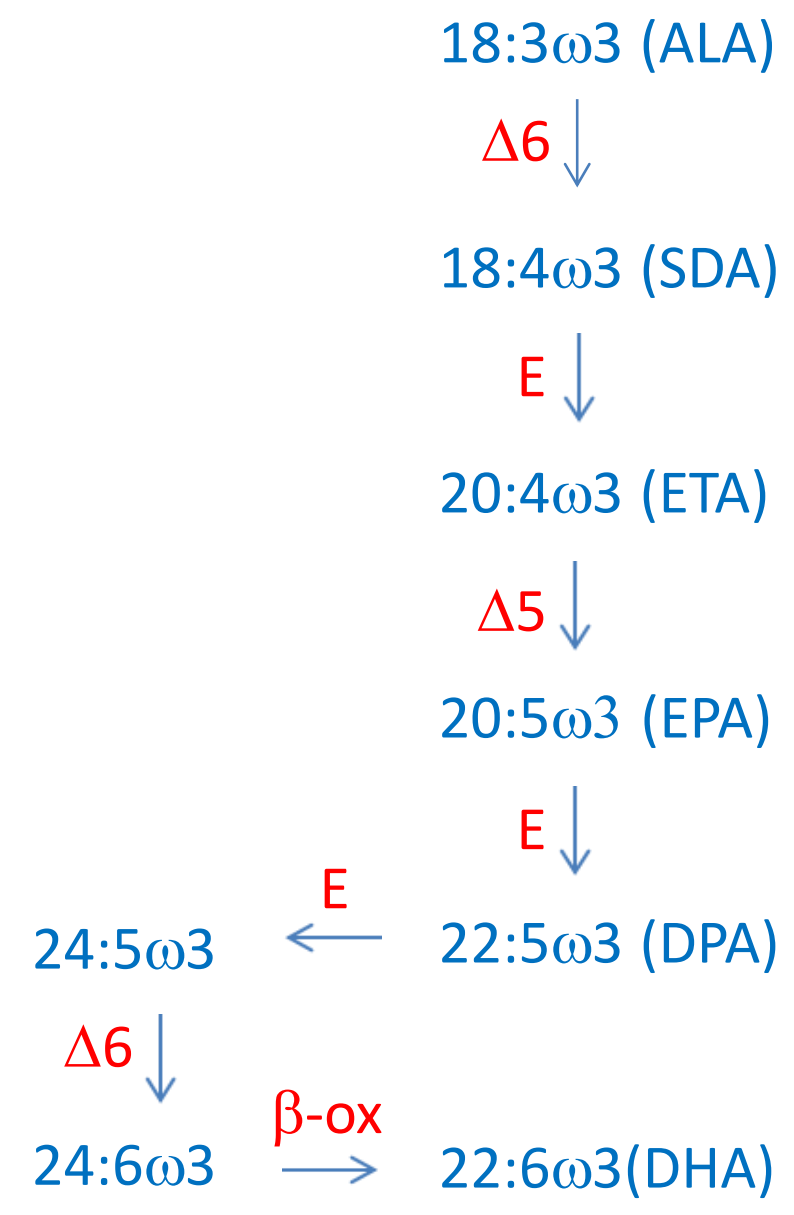

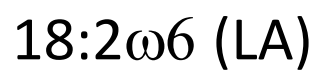

$\Delta 6 \downarrow$

$18: 3 \omega 6$

$\mathrm{E} \downarrow$

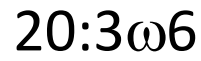

$\Delta 5 \downarrow$

20:4 $\omega 6$ (ARA)

$E \downarrow$
$22: 4 \omega 6 \stackrel{E}{\longrightarrow} 24: 4 \omega 6$

$\Delta 6 \downarrow$

$22: 5 \omega 6 \quad \stackrel{\beta-0 x}{\longleftarrow} 24: 5 \omega 6$

Fig. 1 
4-HpDoHE, 7-HpDoHE

resolvins $D$
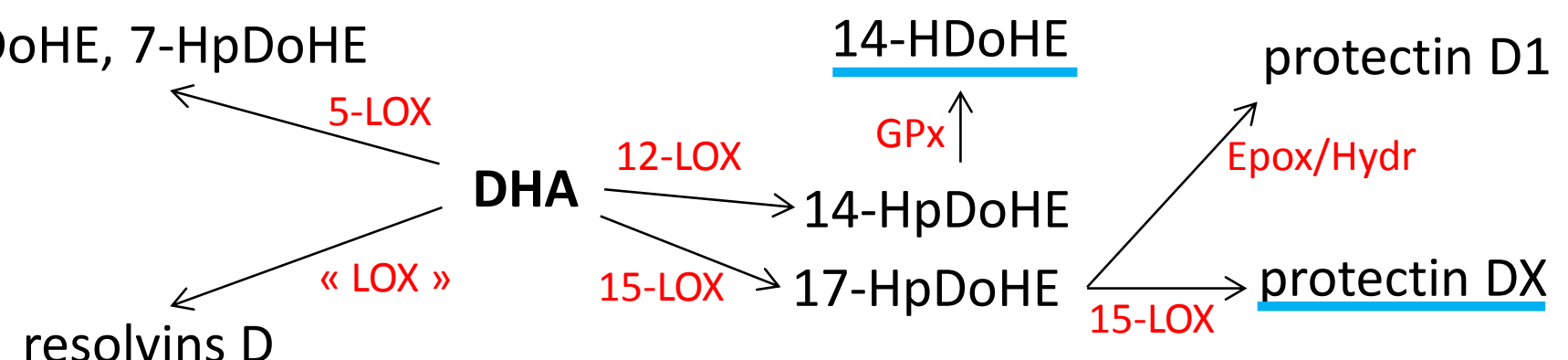

12-HEPE

GPx $\uparrow$

12-LOX $\rightarrow 12-\mathrm{HpEPE}$

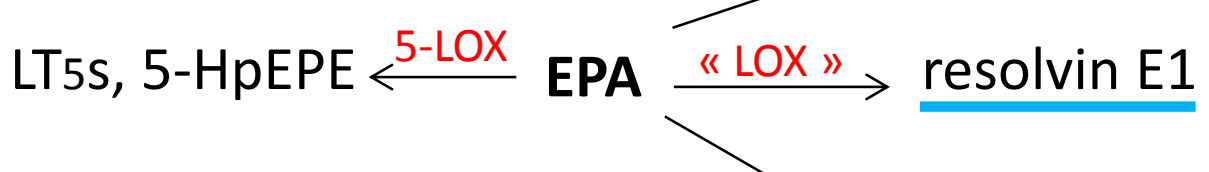

13-HOTE

ALA $\stackrel{15-\text { LOX }}{\longrightarrow}$ 13-HpOTE, linotrins

LT4S, 5-HpETE $\stackrel{5-L O X}{\longleftarrow}$ ARA

$$
\stackrel{\text { 12-LOX }}{\longrightarrow} \text { 12-HpETE } \stackrel{\text { GPx }}{\longrightarrow} \text { 12-HETE }
$$

Fig. 2 

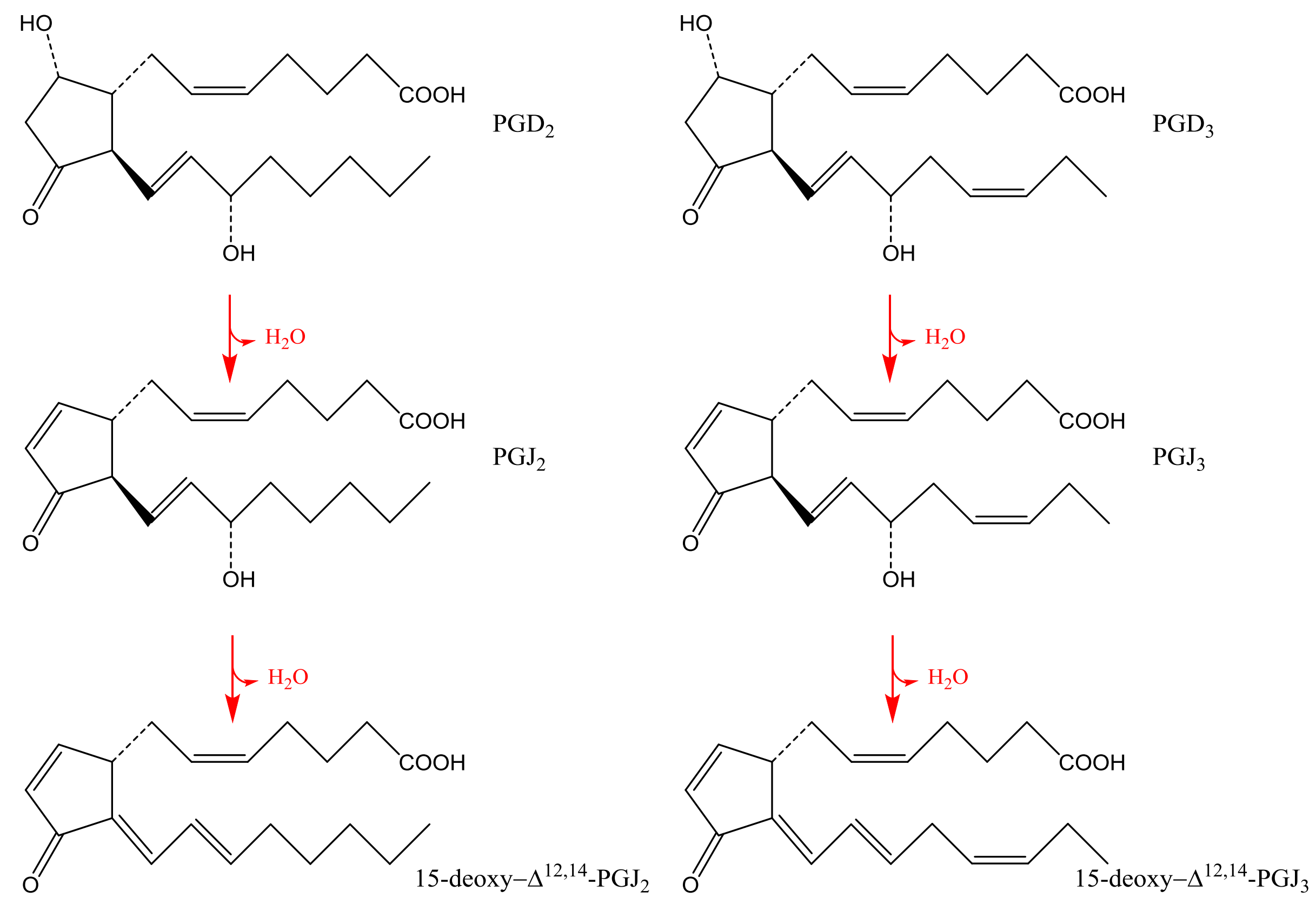

Fig .3 

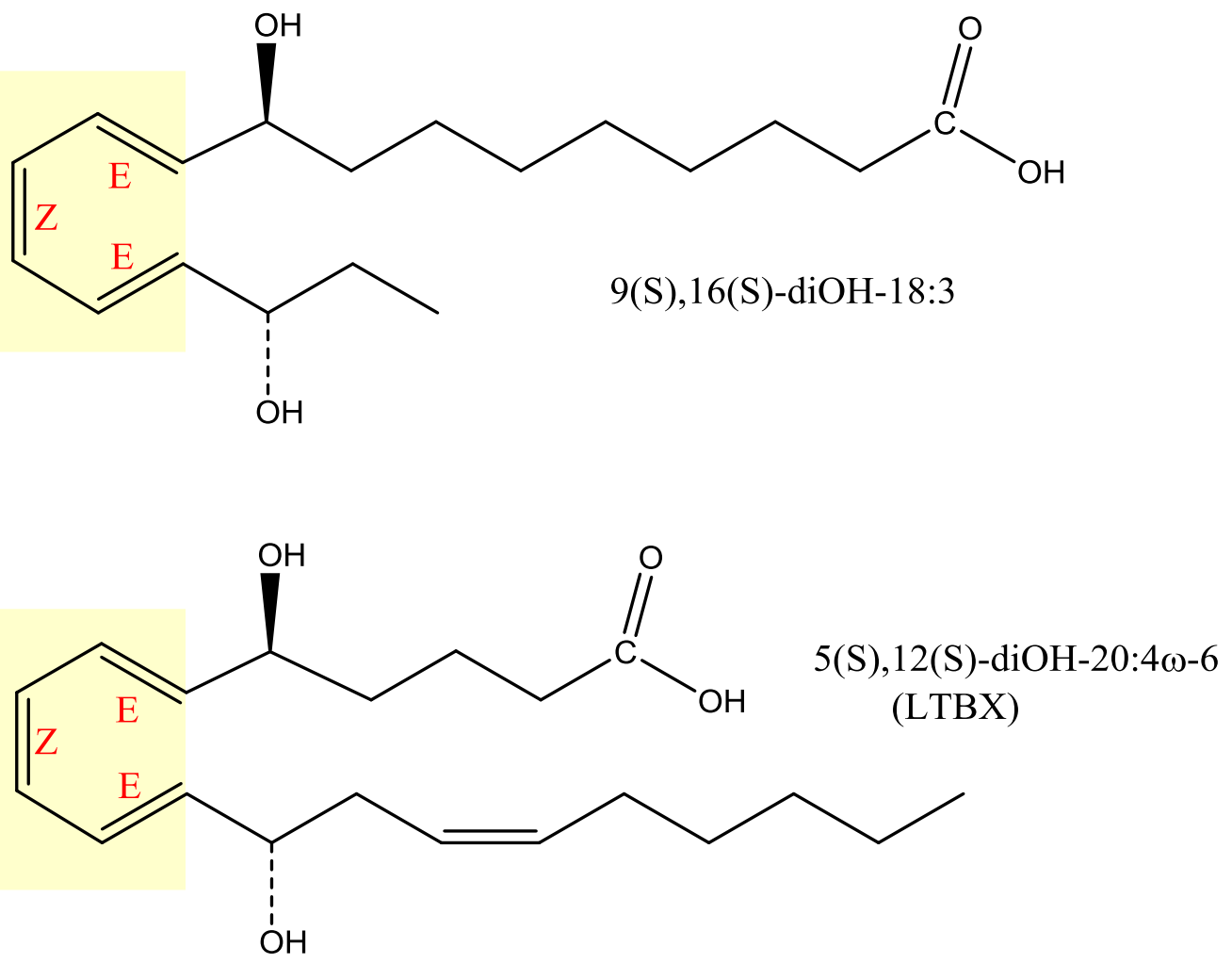

Fig. 4

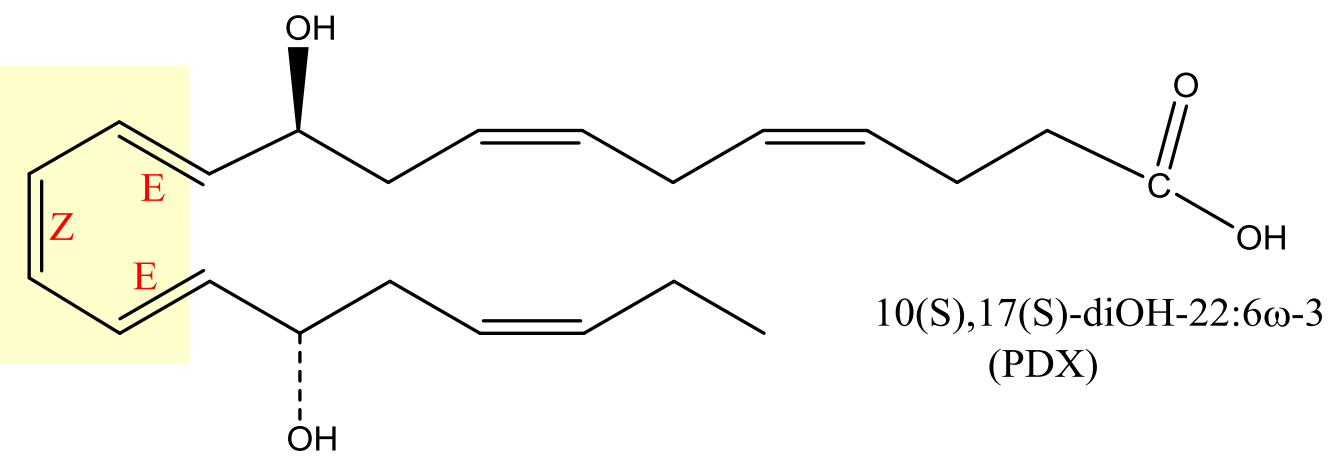


$\omega-6$ fatty acids $\longrightarrow$ 4-hydroxy-nonenal

$\omega-3$ fatty acids $\longrightarrow$ 4-hydroxy-hexenal

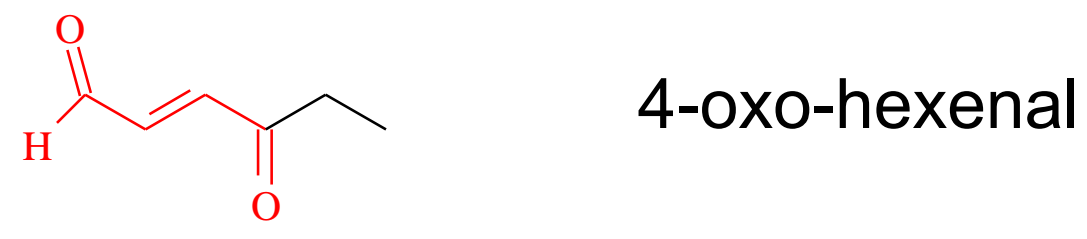

Docosahexaenoic acid

Fig. 5

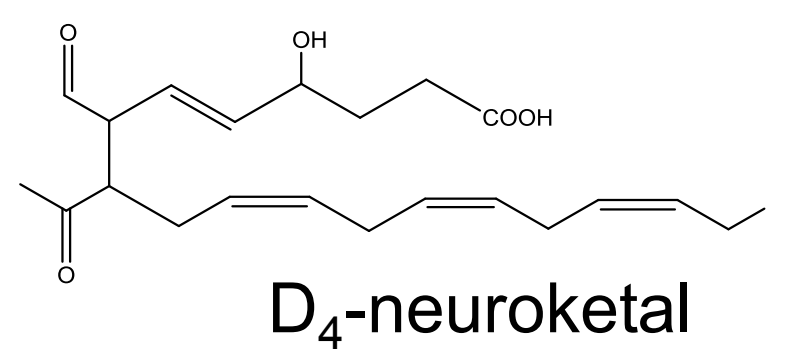

other neuroketal regioisomers 


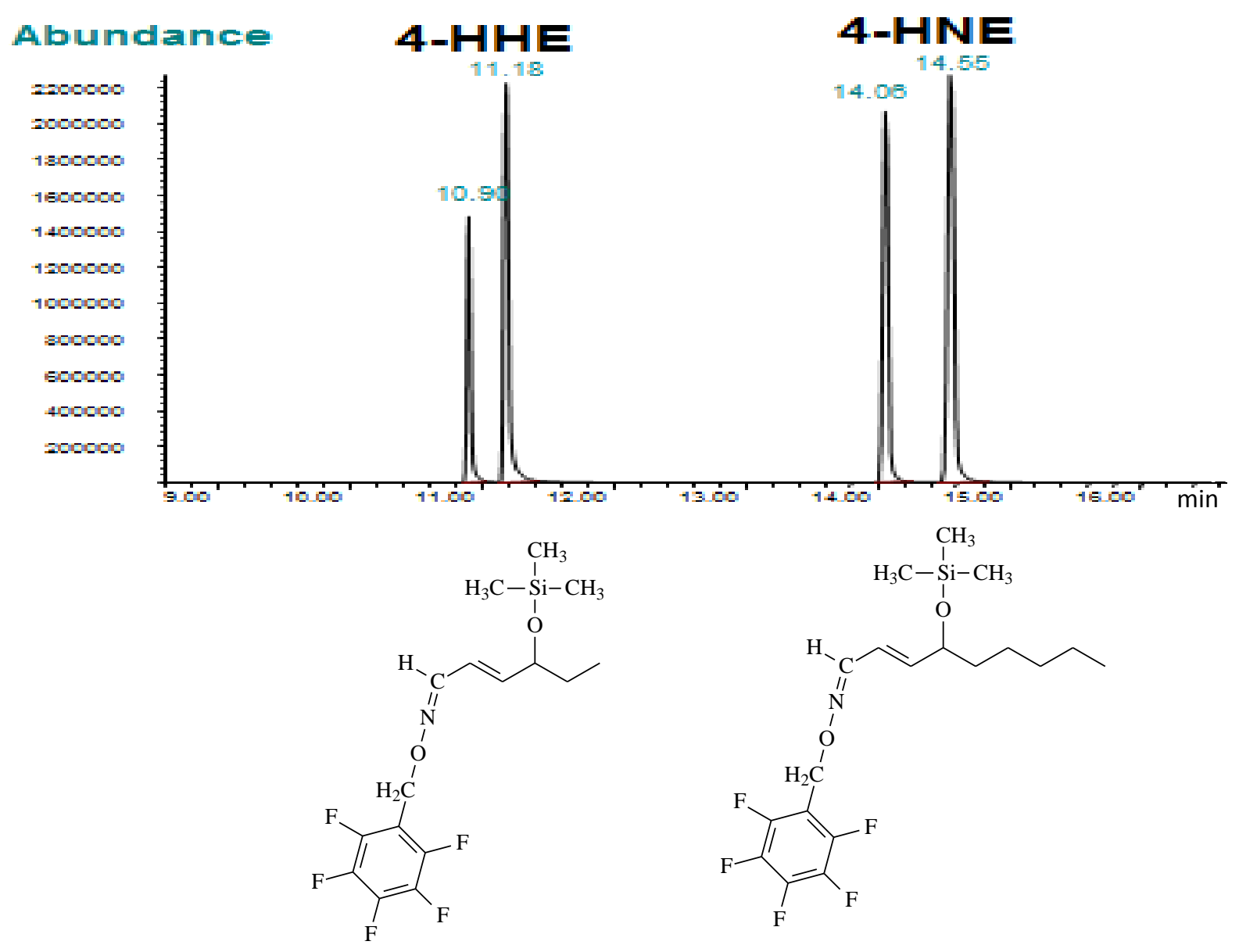

Fig. 6 